A statistical subgrid-scale algorithm for precipitation

formation in stratiform clouds in

the ECHAM5 single column model

Journal Article

Author(s):

Jess, Stephanie; Spichtinger, Peter; Lohmann, Ulrike (D)

Publication date:

2011

Permanent link:

https://doi.org/10.3929/ethz-b-000043816

Rights / license:

Creative Commons Attribution 3.0 Unported

Originally published in:

Atmospheric Chemistry and Physics 11(3), https://doi.org/10.5194/acpd-11-9335-2011 
Atmos. Chem. Phys. Discuss., 11, 9335-9374, 2011

www.atmos-chem-phys-discuss.net/11/9335/2011/

doi:10.5194/acpd-11-9335-2011

(c) Author(s) 2011. CC Attribution 3.0 License.

\section{A statistical subgrid-scale algorithm for precipitation formation in stratiform clouds in the ECHAM5 single column model}

S. Jess ${ }^{1}$, P. Spichtinger ${ }^{1,{ }^{*}}$, and U. Lohmann ${ }^{1}$

${ }^{1}$ ETH Zurich, Institute for Atmospheric and Climate Science, 8092 Zurich, Switzerland now at: Institute for Atmospheric Physics, Johannes Gutenberg-University, Mainz, Germany

Received: 12 November 2010 - Accepted: 18 February 2011 - Published: 22 March 2011 Correspondence to: S. Jess (stephanie.jess@env.ethz.ch)

Published by Copernicus Publications on behalf of the European Geosciences Union.

Sub-column algorithm in

ECHAM5-HAM

S. Jess et al.

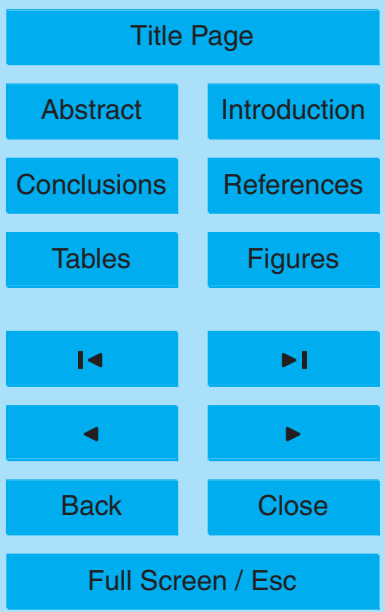

Printer-friendly Version

Interactive Discussion 


\section{Abstract}

Cloud properties are usually assumed to be homogeneous within the cloudy part of the grid-box, i.e. subgrid-scale inhomogeneities in cloud cover and/or microphysical properties are often neglected. However, precipitation formation is initiated by large 5 particles. Thus mean values are not representative and could lead to a delayed onset of precipitation.

For a more physical description of the subgrid-scale structure of clouds we introduce a new statistical sub-column algorithm to study the impact of cloud inhomogeneities on stratiform precipitation. Each model column is divided into $N$ independent sub-columns with sub-boxes in each layer, which are completely clear or cloudy. The cloud cover is distributed over the sub-columns depending on the diagnosed cloud fraction. Mass and number concentrations of cloud droplets and ice crystals are distributed randomly over the cloudy sub-columns according to prescribed probability distributions. Shapes and standard deviations of the distributions are obtained from aircraft observations.

We have implemented this sub-column algorithm into the ECHAM5 global climate model to take subgrid variability of cloud cover and microphysical properties into account. Simulations with the Single Column Model version of ECHAM5 were carried out for one period of the Mixed-Phase Polar Arctic Cloud Experiment (MPACE) campaign as well as for the Eastern Pacific Investigation of climate Processes (EPIC) campaign. Results with the new algorithm show an earlier onset of precipitation for the EPIC campaign and a higher conversion of liquid to ice for the MPACE campaign, which reduces the liquid water path in better agreement with the observations than the original version of the ECHAM5 model.

\section{ACPD}

$11,9335-9374,2011$

\section{Sub-column algorithm in \\ ECHAM5-HAM}

S. Jess et al.

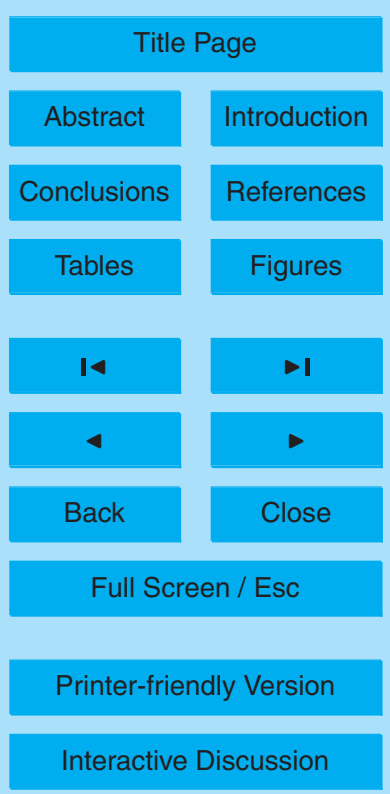




\section{Introduction}

Clouds are one fundamental component of the climate system. They are important regulators of the radiation budget (Kiehl and Trenberth, 1997) and the hydrological cycle (Chahine, 1992). The mean global cloud cover amounts to 60-70\% (Raschke et al., 5 2005). Global climate models (GCM) that simulate the future climate are limited to a coarse resolution on the order of $100 \mathrm{~km}$ horizontal grid space due to computational costs. One key issue for improving the representation of clouds in large-scale models is their inhomogeneity: GCMs use grid mean quantities of cloud properties to calculate cloud microphysical and macrophysical processes, i.e. they represent layers of clouds, which are homogeneous with respect to microphysical properties (e.g. mass and number concentration of cloud droplets and ice crystals). In nature, however, clouds are inhomogeneous in terms of microphysical properties. Larson et al. (2001) stated that models using convex autoconversion functions like the ECHAM model to parameterize the precipitation formation underpredict autoconversion rates. The bias is corrected by tuning parameters, which artificially increase the amount of rain formed. Rotstayn (2000) studied the impact of tuned autoconversion rates in climate models. He found that including some part of subgrid variability in liquid water content into the parameterization of autoconversion of Manton and Cotton (1977) permits to increase the threshold radius above which autoconversion commences. This leads to a more physically based threshold than Rotstayn (2000) used before. Jakob and Klein (2000) showed that parameterizations considering the cloud-precipitation overlap inside a grid-box can partly account for deficiencies in evaporation and accretion rates. Morrison and Gettelman (2008) considered subgrid variability of liquid water content in their cloud microphysics scheme. The largest sensitivity was found in the autoconversion rate due to its high nonlinearity.

Neglecting subgrid variability also leads to errors in radiative properties. Ignoring inhomogeneities can cause solar albedo biases in models (Pincus et al., 1999; Carlin et al., 2002). A deeply irregular medium of a given mean optical thickness has

\section{Sub-column algorithm in \\ ECHAM5-HAM}

S. Jess et al.

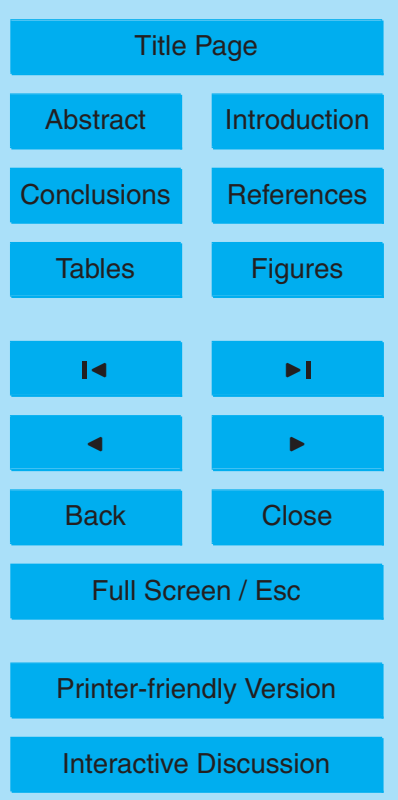


a lower mean albedo than a horizontally homogeneous medium of the same optical thickness (Weinman and Swarztauber, 1968). The huge variability of the cloud structure at different altitudes is partly responsible for the difficulty in representing clouds in GCMs correctly. It can cause errors in the development of microphysical properties like 5 droplet and ice crystal growth and also number concentration because subgrid variability is not well represented. Mean values for cloud variables at each grid point neglect the natural variations and therefore important information will be lost. This shortcoming could lead to uncertainties regarding the equilibrium climate for a doubling of $\mathrm{CO}_{2}$ (Tsushima et al., 2006). The precipitation formation in ECHAM5 is currently calculated 10 using mean values of the cloud condensate in the cloudy part of the grid-box. However, mean values in a grid-box are not representative for the formation of precipitation as all collection processes start with the large particles in the cloud and more than one cloud could occupy a grid cell of a GCM. Also the treatment of precipitation is not handled accurately in the present model configuration (Fig. 1a). One solution of a more accurate treatment is shown in Fig. 1b (details later).

The fluxes from above are able to interact with the entire cloudy part of the grid box in the level below in the present model configuration. For example the accretion of cloud droplets by rain is calculated for the whole cloudy part and is then weighted with the minimum of precipitation fraction and cloud cover. This leads to errors if the cloud cover in the level below is different from the cloud cover above because clouds are inhomogeneous. If ice crystals sediment into a lower liquid cloud containing supercooled water droplets, the droplets may be converted into ice crystals by the Bergeron-Findeisen process (Baker, 1997). Therefore, it depends crucially on the vertical distribution of the cloud if ice crystals falling into the lower cloud initiate precipitation or sublimate in 25 a cloud-free region.

There are different possibilities to include subgrid variability into a large scale model. Some of them are listed below.

1. In general, the distinction of cloud free and cloudy parts in a grid box accounts for some unresolved subgrid variability. An improvement is that the

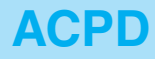

$11,9335-9374,2011$

\section{Sub-column algorithm in \\ ECHAM5-HAM}

S. Jess et al.

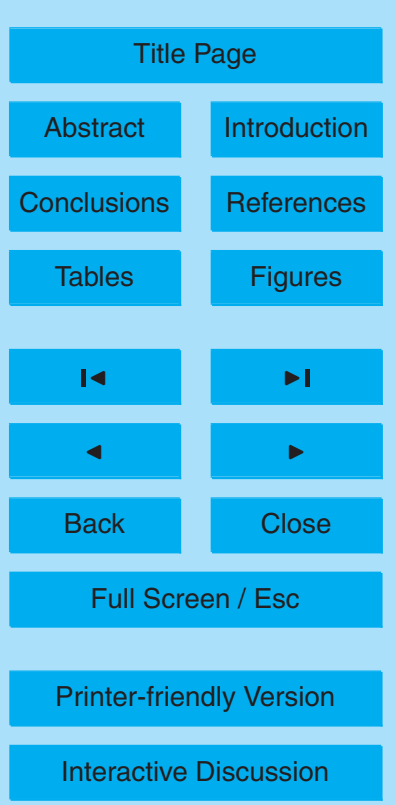

Interactive Discussion 
subgrid-scale distribution of clouds can be derived within the framework of a statistical-dynamical approach, e.g., Tompkins (2002), where the probability density function (PDF) approach uses a beta distribution for the total water mixing ratio and predicts its shape parameters from processes such as deep convection, turbulence and microphysics.

2. The Monte Carlo Independent Column Approximation (MclCA) (Barker et al., 2002) could be applied to compute domain-averaged, broadband radiative flux profiles. The calculation of the radiative fluxes is separated into the clear-sky and the cloudy part of the grid-box for which different possible cloud states could be assumed. For instance, each column of the model is divided into a number of sub-columns (Pincus et al., 2003). The broadband fluxes are calculated separately by performing 1-D radiative transfer calculations on each sub-column and the domain-average fluxes are then obtained. Räisänen et al. (2004) used the sub-column approach explained above for the radiation scheme of the ECMWF model. Cloud properties are distributed with PDFs into the cloudy sub-boxes of each layer to account for horizontal variability.

Another realization of this sub-column approach was used by Jakob and Klein (1999) in a subgrid-scale precipitation model, which resolves the vertical variation of cloud fraction. The subgrid model divides the grid-boxes into homogeneous columns with sub-boxes, which are either completely clear or cloudy. The mean cloud condensate within the cloudy part of the entire grid box is used for each cloudy sub-box. In a next step the microphysical parameterization is calculated separately and independently for each column of sub-boxes.

3. The superparameterization of Grabowski (2001) is a possibility to couple smallscale processes with the large-scale dynamics. Here a two-dimensional cloud resolving model is run in each column of a three-dimensional model. The deterministic method of the superparameterization was used for processes related to atmospheric moist convection and the use of a multi-scale framework. The

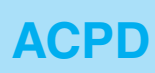

$11,9335-9374,2011$

\section{Sub-column algorithm in \\ ECHAM5-HAM}

S. Jess et al.

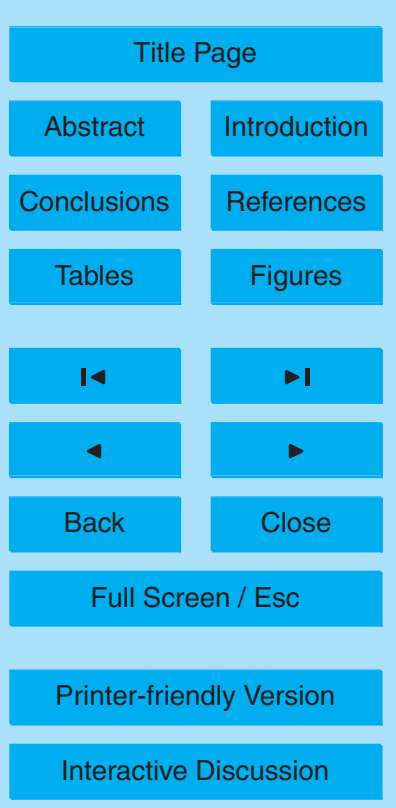


scheme permits to simulate e.g. deep convection, fractional cloudiness and cloud overlap explicitly, however with high computational demand.

In this study, the cloud generator as introduced by Jakob and Klein (1999) and Räisänen et al. (2004) is used to capture some of the unresolved subgrid variability 5 of clouds in the ECHAM5 GCM with emphasis on precipitation formation.

Jakob and Klein (1999) show that the subgrid model calculates less evaporation in the middle troposphere in the tropics resulting in more realistic simulations than without this treatment. The findings of Räisänen et al. (2004) indicate that biases in radiative fluxes and heating rates could be reduced by $25-50 \%$ as compared to studies with 0 horizontally homogeneous clouds.

Compared to the superparameterization of Grabowski (2001), the algorithm used in this study to include subgrid variability is not deterministic but statistical and does not involve coupling to the dynamics, but primary addresses microphysical processes of stratiform clouds. The sub-column algorithm has no time-dependency and the subcolumns representing one column of a GCM are horizontally independent. We introduce inhomogeneities in the microphysical properties of stratiform clouds, which then affect precipitation formation. Distributions of cloud properties are considered instead of averaged in-cloud values used by Jakob and Klein (1999).

The observations of the Eastern Pacific Investigation of Climate processes (EPIC) 20 campaign (Bretherton et al., 2004) and the Mixed-Phase Polar Arctic Cloud Experiment (MPACE) campaign (Verlinde et al., 2007) are used to validate the Single Column Model (SCM) simulations.

Section 2 explains the model physics while Sect. 3 documents the algorithm. The results are displayed in Sect. 4 followed by the discussion of the results in Sect. 5 . 25 Sensitivity studies of the algorithm are described in Sect. 6 and finally conclusions are given in Sect. 7.

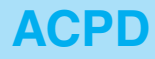

11, 9335-9374, 2011

\section{Sub-column algorithm in \\ ECHAM5-HAM}

S. Jess et al.

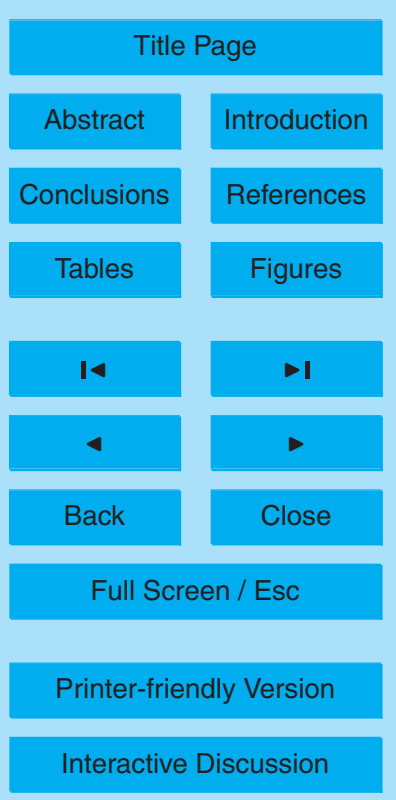




\section{Model description}

We use the ECHAM5 GCM (Roeckner et al., 2003) to investigate the effects of heterogeneous cloud properties on precipitation formation for stratiform clouds. The version of ECHAM5 used in this study is described in Lohmann et al. (2008). The stratiform 5 cloud scheme uses prognostic equations for water vapor, liquid and ice, bulk cloud microphysics (Lohmann and Roeckner, 1996) and a statistical cloud cover scheme (Tompkins, 2002). Phase changes between the water components and precipitation processes (autoconversion, accretion, aggregation) are considered in the cloud scheme. It contains the evaporation of rain, melting and sublimation of snow and cloud ice as well as sedimentation of cloud ice. Prognostic equations of the number concentrations of cloud droplets and ice crystals in stratiform clouds are used and ECHAM5 has been coupled to the aerosol scheme HAM (Stier et al., 2005). The autoconversion scheme of Khairoutdinov and Kogan (2000) was chosen for all simulations. Additionally for a consistent use of the sub-column algorithm, the sequence of cloud microphysical 15 calculations is changed as compared to the original version. Condensation and deposition is calculated first in order to obtain the liquid and ice water content which can then be distributed over the cloudy sub-boxes in the sub-columns.

\section{Sub-column algorithm for microphysics}

The basic idea of the algorithm is the following: first, each grid box is divided into 20 a number $N$ of homogeneous and independent sub-columns (see Fig. 1b). Second, the number of cloudy sub-boxes in each layer is defined by the nearest integer of the product of $N$ sub-columns and the diagnosed cloud fraction in each layer. In this study a maximum-random overlap assumption for the vertical distribution of clouds is used following Jakob and Klein (1999). Third, the clouds are distributed depending on the overlap assumption. The sub-boxes are filled in a left to right order fullfilling the overlap condition (as shown in Fig. 4 in Jakob and Klein, 1999). After determination of the number of cloudy sub-boxes the cloud condensate (ice water content (IWC), liquid

\section{Sub-column algorithm in \\ ECHAM5-HAM}

S. Jess et al.

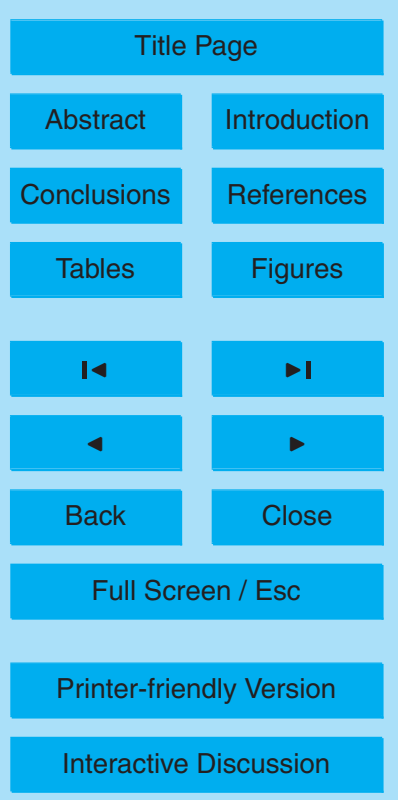


water content (LWC), ice crystal number concentration (ICN) and cloud droplet number concentration (CDNC)) is allocated for the cloudy sub-boxes in a fourth step. We use a log-normal size distribution with prescribed standard deviations for IWC, LWC, ICNC and CDNC taken from atmospheric measurements for the defined cloud properties 5 instead of using constant values for each cloudy sub-box as done by Jakob and Klein (1999).

Figure 2 shows a cumulative frequency distribution. The y-axis is defined between 0 and 1 and is divided into equally sized bins. A random number (e.g. 0.5, respectively 0.7 as highlighted in Fig. 2) decides which corresponding value on the $x$-axis (in 10 this case $1 \mathrm{mg} \mathrm{kg}^{-1}$, respectively $2 \mathrm{mg} \mathrm{kg}^{-1}$ ) is taken and allocated to the given cloudy sub-box. Additionally a vertical coherence between the cloud properties is assumed according to measurements of Hogan and Illingworth (2003). Analysis of 18 months RADAR data over Chilbolton, England, led to a parameterization of the vertical correlation of ice water content:

$15 \log _{10} \Delta z_{0}=0.3 \log _{10} d-0.031 s-0.315$

where $\Delta z_{0}$ is the decorrelation depth in $\mathrm{km}$ describing the strength of the correlation of the ice water content in two adjacent layers, $d$ is the model horizontal resolution in $\mathrm{km}$ and $s$ is the vertical wind shear of the horizontal wind in units of $\mathrm{m} \mathrm{s}^{-1} \mathrm{~km}^{-1}$. The correlation $c(z)$ has values between 0 and 1 .

20 $\quad c(z)=\exp \left(-\frac{\Delta z}{\Delta z_{0}}\right)$

where $\Delta z$ describes the vertical level separation in $\mathrm{km}$. The correlation is assumed to be valid for mass and number concentration of both ice and water clouds since no separate parameterization for water clouds is available. Correlations between mass and number concentrations are not considered, because assuming a correlation between them assumes that the particle size does not vary. In the algorithm, the correlation is included as follows: The correlation $c(z)$ is first calculated for all pairs of cloudy layers.

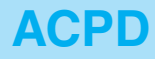

$11,9335-9374,2011$

\section{Sub-column algorithm in \\ ECHAM5-HAM}

S. Jess et al.

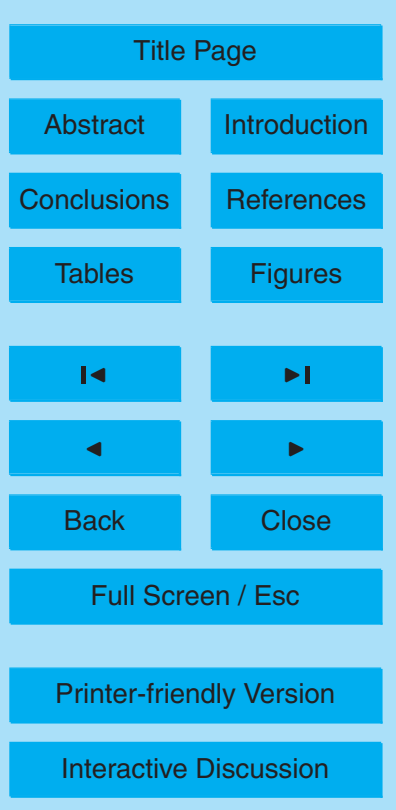

Interactive Discussion 
If two cloudy layers are adjacent, then a random number is taken. If the random number is larger than the correlation, then the same cloud condensate or number concentration is filled into the sub-box below. If the random number is lower than the correlation, than a value from the log-normal distribution is chosen and filled into the cloudy sub-box 5 below according to Räisänen et al. (2004).

The cloud properties of the last cloudy sub-box in each layer are chosen such that the in-cloud mean properties (IWC, LWC, ICNC and CDNC) are conserved. If the resulting radius exceeds $100 \mu \mathrm{m}$ for ice crystals or $25 \mu \mathrm{m}$ for cloud droplets, respectively, the random distribution including the vertical correlation is repeated for the whole layer. If 10 the defined radius interval could not be found after some iterations, the homogeneous distribution of Jakob and Klein (1999) is taken instead. Then, the mean liquid or ice properties as calculated by the model are assigned to all the cloudy sub-boxes in this layer.

After the distribution of the cloud variables all microphysical processes are calculated 15 for each sub-column separately. At the end of the time step averaged variables over all sub-boxes in each layer are calculated for further computation regarding transport, radiation or interactions with aerosols. With this method subgrid-scale variability of cloud microphysical parameters can be considered in the simulation. Hence, cloud processes are treated more physically.

20 There are no horizontal fluxes connecting the sub-columns with each other and no time history of the sub-columns from the previous time step is stored. After each time step the distribution of the cloud properties restarts randomly, because the emphasis of this study is based on the precipitation formation process.

By including cloud inhomogeneities we assume that the formation of precipitation could be triggered earlier, because autoconversion and aggregation are nonlinear processes. This could affect the cloud lifetime. For example the precipitation formation process via the warm phase is proportional to the cloud liquid water mixing ratio to the power 2.5 and inversely proportional to the number concentration of cloud droplets to the power 1.8 .

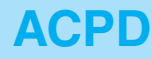

11, 9335-9374, 2011

\section{Sub-column algorithm in \\ ECHAM5-HAM}

S. Jess et al.

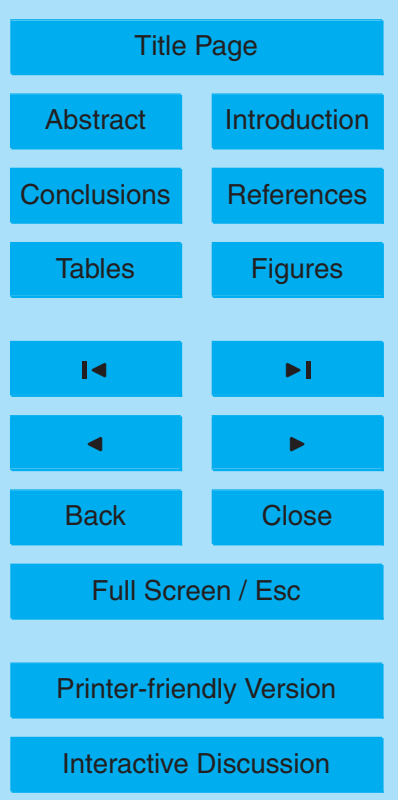




\section{Results}

\subsection{Set-up of the simulations}

Three different simulations as summarized in Table 1 were performed for the EPIC case study and the MPACE period A case study: the first simulation is the reference

5 run REF with the original model version ECHAM5.5 and the changed order of cloud processes as described in Sect. 2. In a second simulation HOM, the sub-column algorithm was used with $N=20$ sub-columns. Here the means of all cloud properties are taken for all cloudy sub-boxes (IWC, LWC, ICNC and CDNC are the same in every cloudy sub-layer) following Jakob and Klein (1999). Thus the determined vertical cloud overlap alone is responsible for the changes in cloud properties in simulation HOM. In simulation HET as described in Sect. 3, log-normal distributions of IWC, LWC, ICNC and CDNC are used to represent horizontal inhomogeneities of cloud properties. The standard deviations for the distributions are taken from measurements over Canada analyzed by Gultepe and Isaac (2004) for CDNC and Gultepe and Isaac (1996) for LWC.

15 For $\sigma_{\mathrm{CDNC}}$ only the distribution from Fig. 2c of Gultepe and Isaac (1996) because both field campaigns used here took place over oceans. $\sigma_{\mathrm{IWC}}$ is derived from the average of Table 3 (Gultepe and Isaac, 1996). For the ice properties the values were calculated from measurements of frequency distributions of data from the Interhemispheric differences in cirrus properties from anthropogenic emissions (INCA) campaign over Punta Arenas in Chile and Prestwik in Scotland during 2000 (Gayet et al., 2004) and data from Schiller et al. (2008). The standard deviations were obtained as $\sigma_{\mathrm{LWC}}=1.5$ as a mean over all measurements and $\sigma_{\mathrm{CDNC}}=1.6$ for measurements over the oceans. The standard deviations for IWC and ICNC were obtained from the above mentioned measurements to be $\sigma_{\mathrm{IWC}}=1.25$ for IWC and $\sigma_{\mathrm{ICNC}}=1.1$ for ICNC. All simulations 25 were run with a minimum cloud droplet number concentration of $10 \mathrm{~cm}^{-3}$ instead of $40 \mathrm{~cm}^{-3}$ used in Lohmann et al. (2008). in order not to truncate the distribution too early and to assign a homogeneous distribution too often. Moreover the default value of $40 \mathrm{~cm}^{-3}$ is quite high as compared to the measurements considered in this study.

\section{Sub-column algorithm in ECHAM5-HAM}

S. Jess et al.

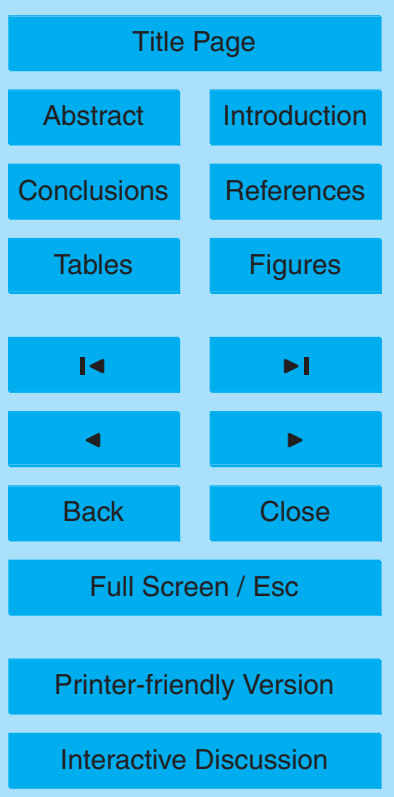

Interactive Discussion 
The simulations for EPIC have been carried out at $20^{\circ} \mathrm{S}$ and $85^{\circ} \mathrm{W}$ and for MPACE they were performed for the station Barrow at $71^{\circ} 18^{\prime} \mathrm{N}$ and $156^{\circ} 46^{\prime} \mathrm{W}$. The SCM was run with 31 vertical levels and a time step of $15 \mathrm{~min}$. In order to evaluate the impact of the subgrid variability no retuning of the model has been done.

\section{$5 \quad 4.1 .1 \quad$ EPIC}

Since the sub-column algorithm is applicable for all types of clouds, we start our verification with a pure liquid cloud, i.e. a case from the EPIC campaign (Bretherton et al., 2004). Stratocumulus clouds which formed off the coast of Chile were investigated during this campaign.

The observational data used for comparison in this study include cloud fraction, precipitation, liquid water path (LWP) and CDNC. Here the cloud fraction is a three hourly mean of the ceilometer returned cloud base. The surface precipitation rate is synthesized from a microwave millimeter cloud radar (MMCR). The estimated uncertainty in the rain rate is approximately a factor $2-3$ (Comstock et al., 2004). LWP was diag15 nosed from microwave radiometer following the procedure of Hogg et al. (1983). The uncertainty of the retrievals of LWP is about $30 \mathrm{~g} \mathrm{~m}^{-2}$ (Zuidema et al., 2005). CDNC is extrapolated from daytime values, which are derived following Dong and Mace (2003) using simultaneous measurements of cloud thickness, LWP and optical depth. The overall uncertainty in CDNC is $25 \%$ (Dong and Mace, 2003).

20 The SCM is initialized using the surface pressure and the vertical profiles of temperature, specific humidity and horizontal wind speed from radio soundings launched during the campaign. The large-scale advection of temperature and specific humidity as well as large-scale subsidence was derived from ECMWF reanalysis (Bretherton et al., 2004). In addition, an aerosol concentration of $300 \mathrm{~cm}^{-3}$ for particles with

radii $>35 \mathrm{~nm}$ is prescribed to obtain the observed cloud droplet number concentration of $100-130 \mathrm{~cm}^{-3}$. No advection of cloud properties is available. For calculating the

\section{ACPD}

11, 9335-9374, 2011

\section{Sub-column algorithm in \\ ECHAM5-HAM}

S. Jess et al.

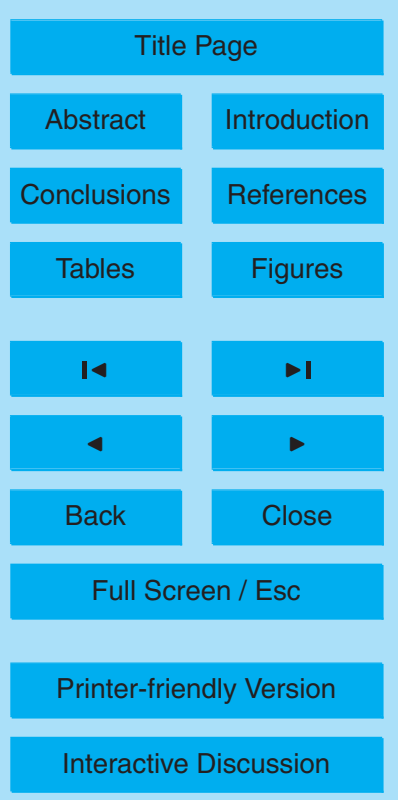


decorrelation depth, the horizontal grid size is needed. According to the geographical position of the campaign at $20^{\circ} \mathrm{S}$ and $85^{\circ} \mathrm{W}$ a horizontal grid size of $d=196 \mathrm{~km}$ is used.

\subsubsection{MPACE}

5 Our next focus is on mixed-phase clouds where the precipitation formation could be initiated via the seeder-feeder process, when ice crystals or rain drops from above fall into a lower cloudy layer. The SCM simulations were performed for one period of MPACE which took place at the Northern slope of Alaska (Verlinde et al., 2007). The forcing from the intercomparison studies (Morrison et al., 2009) is used. All simulations are initialized with radiosounding data from Barrow and are forced with temperature and specific humidity tendencies from ECMWF analysis data. Again no advection of cloud properties is available.

During observation period A (5 October, 14:00 UTC to 8 October, 14:00 UTC) first high pressure over the pack ice was associated with a flow from the east to eastnortheast. A small mid-level trough drifted along the coast and was responsible for moist air in mid- and upper levels. The resulting clouds show a complex, multi-layered structure with ice present throughout the cloud likely sedimenting through the liquid layers (Morrison et al., 2009).

For the MPACE campaign measurements of cloud cover, precipitation, LWP and 20 IWP are used for comparison. The retrievals are based on millimeter wavelength cloud radar, lidar and microwave radiometer measurements. The uncertainties for the observations are $\pm 15 \%$ for the bulk liquid and a factor of two for the bulk ice parameters (Klein et al., 2009). For the precipitation the same uncertainty as for the EPIC case was assumed (factor 2-3). According to the geographical position of the campaign at 25 $71^{\circ} 18^{\prime} \mathrm{N}$ and $156^{\circ} 46^{\prime} \mathrm{W}$ a horizontal grid size of $d=67 \mathrm{~km}$ is used.

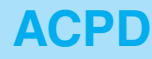

11, 9335-9374, 2011

\section{Sub-column algorithm in \\ ECHAM5-HAM}

S. Jess et al.

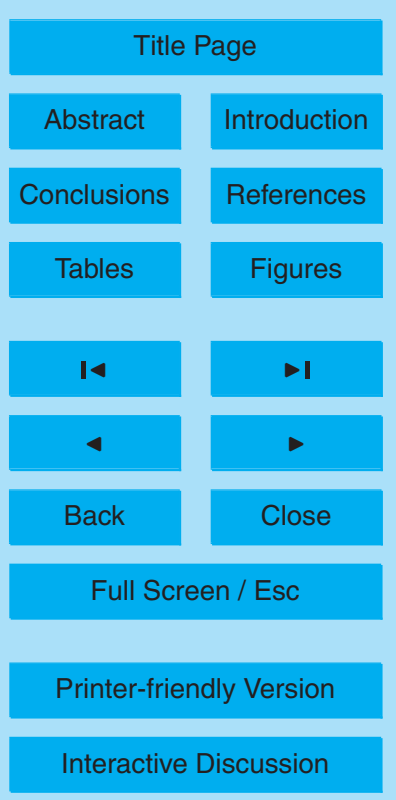




\subsection{Single column model results}

\subsubsection{EPIC}

The stratocumulus cloud had a thickness between $200 \mathrm{~m}$ and $500 \mathrm{~m}$ and was present for the whole period (Fig. 3). The cloud fraction varied between $60 \%$ and $100 \%$. Since

5 the vertical resolution of the model is around $500 \mathrm{~m}$, the vertical extension of the cloud was equal or less the vertical resolution of the model. Hence, small amounts of precipitation formed inside the cloud caused its decay. The period on 17 October with low cloud cover in all simulations could be due to problems in the representation of the meteorological conditions by the forcing data (Posselt and Lohmann, 2008). From 18 October onwards a higher cloud fraction is present in all model simulations. A reduction of cloud cover is mainly calculated with simulation HET due to enhanced precipitation which strongly reduces LWP. In simulations REF and HOM the model preferably calculates overcast conditions for the second part of the period.

The observed LWP shows a large variation with values between 0 and $250 \mathrm{~g} \mathrm{~m}^{-2}$ (Fig. 3). It shows a diurnal cycle and is also influenced by the precipitation formed in the stratocumulus layer. Since the precipitation on 18 and 19 October is lower in the simulations REF and HOM (Fig. 3), LWP remains rather high. LWP in simulation $\mathrm{HET}$ is lower due to higher precipitation rates and the observed characteristics of LWP are better captured. In general, LWP in simulation HET shows better agreement with observations than simulations REF and HOM which can also be seen in the time averaged values for the whole period in Table 3. But the peaks are still overpredicted.

During the period several precipitation events occur with a maximum of $1.8 \mathrm{~mm}$ day $^{-1}$ on 19 October. The precipitation rates in the model simulations are underestimated during the first period, while in the second period beginning on 20 October all simulations strongly overpredict the measured rain rate at the surface (Fig. 3). Precipitation in simulation HET is increased in the beginning of the simulation and also on 18 and 19 October (Fig. 3) because few sub-columns contain sufficient liquid water to initiate the precipitation formation process. Since the cloud is only present in a few layers for

\section{Sub-column algorithm in \\ ECHAM5-HAM}

S. Jess et al.

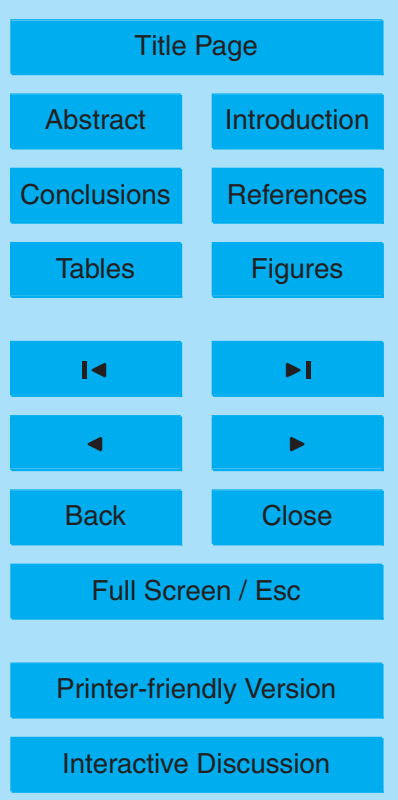


the first time steps of the simulations precipitation strongly reduces the cloud fraction in all simulations (Fig. 3). While precipitation reaches the surface in simulation HET on 16 October, the evaporation rate is stronger in simulations REF and HOM and no precipitation was predicted at the surface. Differences in precipitation between simu5 lations and observations can be caused by under- or overestimation of the internally calculated surface fluxes (Posselt and Lohmann, 2008). On 20 October, precipitation forms earlier in simulation HET but also persists for a longer time because the inhomogeneities are able to produce more continuous precipitation probably in different parts of the cloud. Hence the autoconversion and accretion rates are enhanced in simula10 tion HET. A reduction in the overestimation of the peak precipitation rates is simulated in simulation HET on 20 October as compared to simulation REF and HOM because LWP is not as large in HET as in REF and HOM.

The observed CDNC is a layer-mean and shows high values at the beginning of the period probably caused by advection from the continent, followed by a decrease and 15 a subsequent increase after the precipitation event on 19 October (Fig. 3). Simulated CDNC is in the observed range in the second part of the period in all simulations and differences between the simulations are small.

Figures 4 and 5 show the relationship between LWP and precipitation as well as CDNC and precipitation from observations and the model simulations. The overestimation in LWP is reduced in simulation HET as compared to simulations REF and HOM (Fig. 4). The spread in the simulations for the relationship precipitation and CDNC is larger than for precipitation and LWP (Fig. 5). The relationship between precipitation and LWP is closest to the observations for simulation HET. For the EPIC case the distinction between cloudy and cloud-free sub-boxes with the average cloud condensate according to Jakob and Klein (1999) (HOM) is not sufficient to affect the precipitation rate and hence LWP significantly, but the inhomogeneities included in simulation HET clearly impact the results as compared to REF and HOM. Especially cloud cover is more inhomogeneous during the second part of the simulation and precipitation is enhanced on 18 and 19 October in better agreement with observations while

\section{Sub-column algorithm in ECHAM5-HAM}

S. Jess et al.

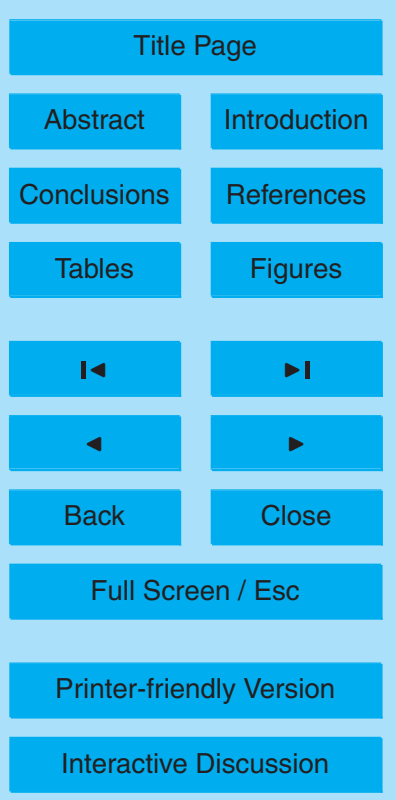

Interactive Discussion 
LWP is reduced. Hence LWP in simulation HET is closer to the measurements than simulations REF and HOM.

\subsubsection{MPACE period A - multi-layer cloud}

The observations show a persistent multi-layer mixed-phase cloud during the whole 5 time that extends up to approximately $500 \mathrm{hPa}$ with a maximum thickness on 7 October (Fig. 6). In all simulations a multi-layered cloud is present, but the modeled clouds are less continuous and have a smaller vertical extension than the observed cloud. The vertical thickness of the cloud is reduced in simulation HET as compared to simulations REF and HOM due to sedimentation of cloud ice.

10 The mixed-phase cloud produces precipitation rates with an observed maximum of $0.17 \mathrm{~mm} \mathrm{~h}^{-1}$ on 7 October (Fig. 6). All simulations overestimate the precipitation rate on the first days of the simulation. They underpredict it on 7 October but the timing of the precipitation peak in simulation HET correlates quite well with the observations, while no precipitation peak is simulated for the simulations REF and HOM. The second precipitation event is captured quite well by all simulations. By including cloud inhomogeneities an earlier precipitation formation and therefore a reduction of the cloud life time is triggered due to sedimentation of ice crystals in simulation HET. For the second precipitation event on 6 October more precipitation is formed in simulation HET which keeps LWP low (Fig. 6). The high overestimation of precipitation in all simulations at the beginning seems to be an initialization problem while the absence of precipitation on 7 October may be caused by not considering the large-scale advection of hydrometeors in the forcing data (Morrison et al., 2009).

The observed LWP consists of two different retrieval methods. One is averaged between the stations Barrow and Oliktok Point (WANG retrieval) and the other is averaged between the stations Barrow, Oliktok Point and Atquasuk (TURNER retrieval) (Turner et al., 2007). Observations of LWP show lower values for the first days and a higher peak on 8 October with a maximum around $150 \mathrm{~g} \mathrm{~m}^{-2}$ for the TURNER retrievals and $250 \mathrm{~g} \mathrm{~m}^{-2}$ for the WANG retrievals (Fig. 6). The simulations REF and HOM slightly

\section{Sub-column algorithm in \\ ECHAM5-HAM}

S. Jess et al.

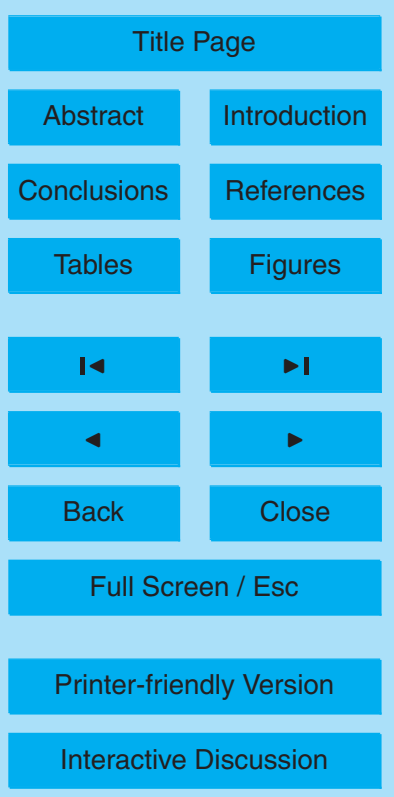


overestimate LWP for the first days while simulation HET shows reduced values in better agreement with the observations. All simulations underpredict LWP on the last simulation day. While precipitation forms via the warm phase at the beginning of the simulations REF and HOM, some cold precipitation forms in case of simulation HET in 5 accordance with observations reporting intermittent precipitation in form of light snow (Morrison et al., 2009). However, the amounts of snow in simulation HET are quite low (not shown).

The observations of ice water path (IWP) are retrieved from RADAR measurements over the station Barrow (SHUPE-TURNER method) (Shupe et al., 2006) and show high 10 values on 6 and 7 October with a maximum of approximately $250 \mathrm{~g} \mathrm{~m}^{-2}$ for 7 October (Fig. 6). The model estimates of IWP do not include snow at the surface. The simulations REF and HOM are not able to form ice until 6 October. The first precipitation peak is partly diagnosed as snow in simulation HET, so the ice formed is already removed from the atmosphere. On 7 October less ice is formed in simulation HET due to more precipitation via the warm phase so that less cloud water is available for freezing. The high amounts of ice in the atmosphere could not be captured in any simulation. Observations report a higher LWP in the shallow cloud on 8 October and a lower LWP in the deeper cloud before. This suggests the impact of seeding of ice from above in reducing LWP in the deeper clouds (Morrison et al., 2009) which also seems to be a problem in the simulations. One probable reason could be that precipitation removes liquid water too fast from the atmosphere so that less liquid water is available for the freezing process. Additionally, ice which formed within one time step may have sedimented and sublimate in subsaturated regions below the cloud. Also hydrometeor advection is not provided in the forcing data. Hydrometeor advection could have occurred on 7 October, where the observations show high amounts of LWP.

In summary, the vertical extension of cloud cover is reduced in simulation HET due to sedimentation of cloud ice which also reduces LWP. Although amounts are small, the inhomogeneities produce more snow than simulations REF and HOM in better agreement with the observed light snow showers (not shown).

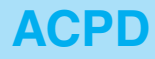

11, 9335-9374, 2011

\section{Sub-column algorithm in \\ ECHAM5-HAM}

S. Jess et al.

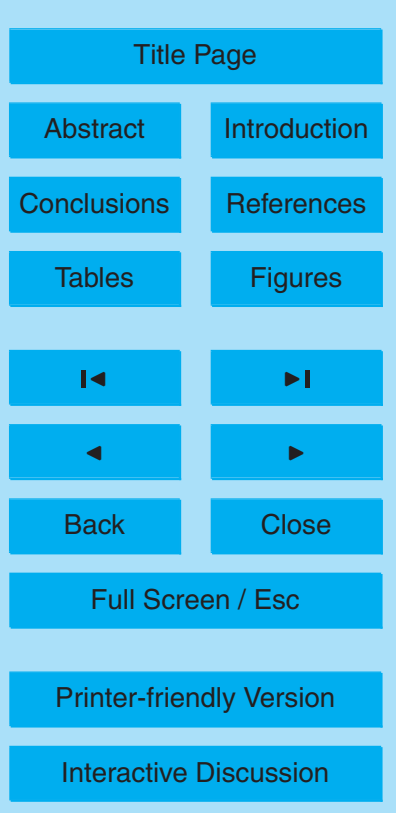




\section{Sensitivity studies}

\subsection{Number of sub-columns}

The distribution of cloud cover is sensitive to the number of chosen sub-columns. The more sub-columns the more accurate is the distribution of cloud cover. For example

5 if the cloud cover is 0.73 and 20 sub-columns are used for the simulation, then 15 of the 20 sub-columns are cloudy which corresponds to a cloud fraction of 0.75 , while in the case of 30 sub-columns 22 out of 30 are cloudy which yields a cloud fraction of 0.733. In case more sub-boxes are cloudy, more precipitation can be formed which can influence the precipitation fraction and LWP. If less then 10 sub-columns are chosen, the cloud cover is distributed with an error that affects the distribution of mass and number concentration inside the cloudy sub-boxes (not shown).

In a sensitivity test the number of sub-columns was changed from 20 sub-columns, which was used in the simulations described above, to values between 21 and 500 for the homogeneous distribution HOM. As compared to the reference run, a homogeneous simulation with 20 sub-columns needs to $10 \%$ more CPU time for the different cases. For 100 sub-columns the CPU time increases by $45 \%$ as compared to the reference version.

A change in the number of sub-columns for the simulation HET shows a stronger increase in the CPU time. As compared to the reference run, the time is increased by 25 to $27 \%$ for the simulation with 20 sub-columns. For 40 sub-columns ( 60 sub-columns) the time required is 46 to $52 \%$ (69 to $106 \%$ ) higher than the CPU time consumed for REF. As explained in Sect. 3, a homogeneous distribution following Jakob and Klein (1999) is chosen if a distribution can not be found after some iterations. For the EPIC campaign about $10 \%$ of the water clouds are distributed homogeneously. $16 \%$ of the water clouds and $22 \%$ of the ice clouds are distributed homogeneously for the MPACE case according to Jakob and Klein (1999) since the cloud is more complex than in the EPIC case study.

\section{Sub-column algorithm in \\ ECHAM5-HAM}

S. Jess et al.

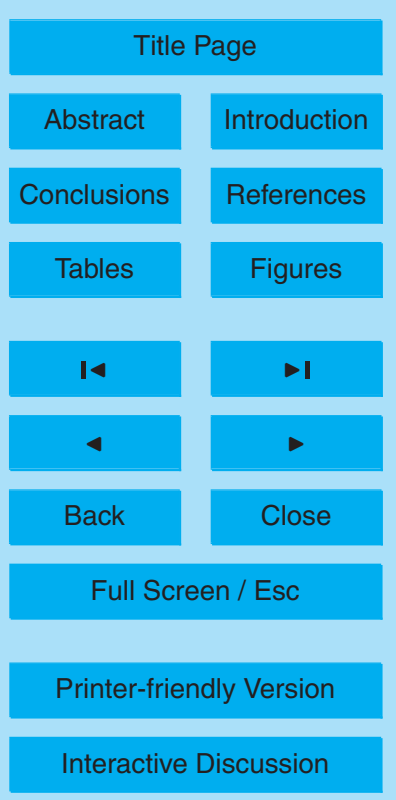


Table 2 summarizes averaged values of cloud cover, LWP, CDNC and precipitation over the period with different number of sub-columns for the EPIC case. Changes in microphysical variables for HOM are small. The odd numbers of sub-columns were chosen to avoid the use of only multiples which produce the same cloud cover and 5 therefore identical results. Largest changes occur between 20 and 21 sub-columns. Here differences in cloud cover are the reason for changes occurring in the microphysical variables. While the averaged values remain approximately the same, small changes occur in the distribution of LWP, CDNC and precipitation during time steps with a cloud cover smaller than overcast conditions. In general, the results converge for 10 an increase in sub-columns, which is also true for simulation HET. Table 2 summarizes examples for the heterogeneous distributions (HET20, HET40, HET60). Differences between 20 and 60 sub-columns are small, while the changes in microphysical variables between 20 and 40 sub-columns are larger due to an earlier increase in cloud cover to overcast conditions on 18 October.

For the MPACE campaign the high precipitation rate at the beginning dominates the averaged cloud properties and therefore differences in the average values are small when changing the number of sub-columns. Due to mainly overcast conditions the sensitivity of the results to the number of sub-columns is even smaller as compared to the EPIC case.

\subsection{Standard deviation of the distributions}

In order to evaluate the impact of the chosen standard deviations for the distributions of mass and number concentrations on the precipitation formation, the applied standard deviations $\sigma_{\mathrm{LWC}}=1.5$ for and $\sigma_{\mathrm{CDNC}}=1.6, \sigma_{\mathrm{IWC}}=1.25$ and $\sigma_{\mathrm{ICNC}}=1.1$ are all set to $\sigma_{\mathrm{CDNC}}=\sigma_{\mathrm{LWC}}=\sigma_{\mathrm{IWC}}=\sigma_{\mathrm{ICNC}}=1.01$ in the simulation HET20 low and doubled in simulation HET20 double to $\sigma_{\mathrm{LWC}}=3.0, \sigma_{\mathrm{CDNC}}=3.2, \sigma_{\mathrm{IWC}}=2.5$ and $\sigma_{\mathrm{ICNC}}=2.2$. To evaluate the change of only one variable the distribution of LWC was held constant for the EPIC case and CDNC was varied from $\sigma_{\mathrm{CDNC}}=1.3$ to $\sigma_{\mathrm{CDNC}}=1.9$.

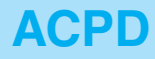

$11,9335-9374,2011$

Sub-column algorithm in

ECHAM5-HAM

S. Jess et al.

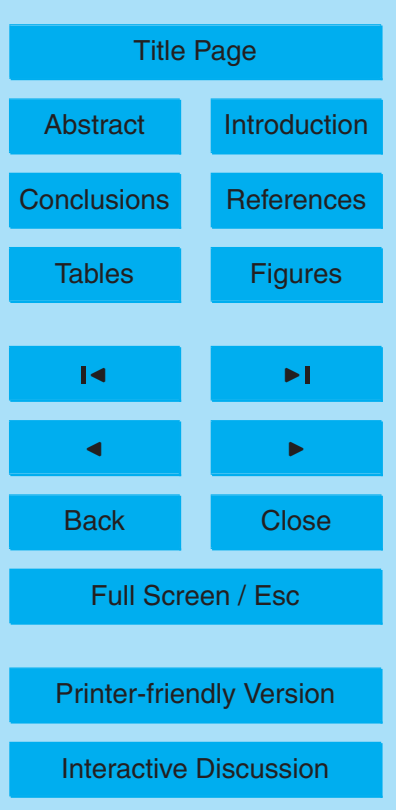


For the MPACE case another experiment was performed where the standard deviations for LWC, IWC and CDNC were fixed but the standard deviation for ICNC is varied from a constant value of 1.1 to values between 1.2 and 1.7 .

For a small value of $\sigma$ the distribution is narrow and is closer to the simulation HOM 5 while for a higher $\sigma$ the distribution becomes broader and a larger range of values is allowed in the different sub-columns.

\subsubsection{EPIC}

The cloud cover for the narrow distribution (HETlow) follows simulation HET for the first part of the simulation but shows mainly overcast conditions for the second period of 10 the simulation (Fig. 7). For the broader distribution of cloud properties (HETdouble) the cloud thickens earlier as compared to the other simulations and mainly overcast conditions dominate during the second part of the simulation as well. The averaged precipitation over the period is higher in simulation HETdouble but simulation HETlow is comparable to simulation HOM where less precipitation is formed at the beginning but more on the last simulation days (see also Table 3). LWP is enhanced in simulation HETlow because the subgrid variability is reduced and the results are close to simulation HOM with less precipitation at the beginning. Due to a higher precipitation rate in simulation HETdouble LWP is consequently lower.

If $\sigma_{\mathrm{CDNC}}$ is changed only (Fig. 8), the timing of cloud thickening on 18 October is afin LWP are smaller for this sensitivity study as compared to changes between the simulations REF and HOM (Table 3). Largest differences occur for the smallest standard deviation. Since the autoconversion rate is proportional to $\mathrm{LWC}^{2.5}$ and $\mathrm{CDNC}^{-1.8}$ in the used parameterization, changes in LWP dominate for a small spread in $\sigma_{\mathrm{CDNC}}$. Differences in CDNC are small and show no clear trend.

In summary, a strong reduction in the standard deviation leads to similar results as obtained with simulation HOM, while an increase in the standard deviation results in more precipitation due to a higher subgrid variability. The broader the distribution

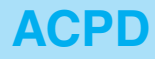

$11,9335-9374,2011$

\section{Sub-column algorithm in \\ ECHAM5-HAM}

S. Jess et al.

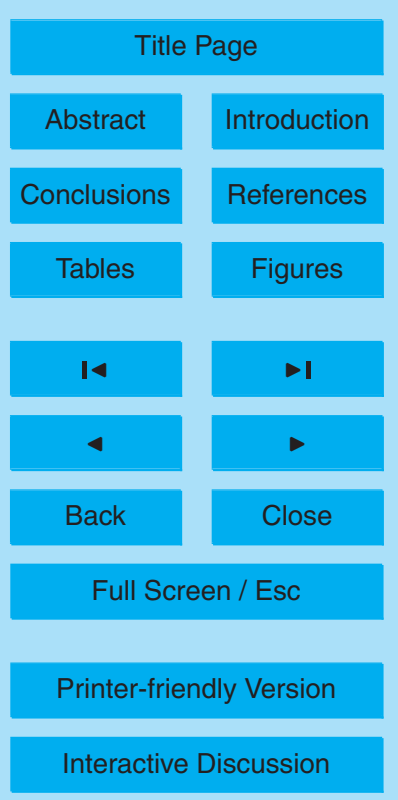


the higher the probability that precipitation is formed in at least one cloudy sub-box resulting in an earlier onset of precipitation at the surface. This can be observed on 20 October, where the precipitation onset is shifted to a later time when the standard deviation is reduced (Fig. 7). A change in $\sigma_{\mathrm{CDNC}}$ mainly affects the cloud cover and the onset and amount of precipitation.

\subsubsection{MPACE period A - multi-layer cloud}

Since the amount of ice is low during MPACE A the sensitivity in IWP is negligible when only $\sigma_{\mathrm{ICNC}}$ is changed, while differences in precipitation are directly linked to changes in LWP. The first precipitation peak is not affected by a change in $\sigma_{\text {ICNC. }}$.

10 A larger spread between the different sensitivity simulations can be observed for a simple change in $\sigma_{\mathrm{CDNC}}$ affecting IWP, LWP and precipitation. Again the smallest and the largest standard deviations show the greatest impact with increased precipitation for the first peak. For $\sigma_{\mathrm{CDNC}}=1.3$ more precipitation is caused via sedimentation of cloud ice and increased warm rain formation while for simulation $\sigma_{\mathrm{CDNC}}=1.9$ more precipitation via the warm phase leads to enhanced surface precipitation. If a broader distribution is used for both mass and number concentration more precipitation forms at an earlier time which reduces LWP. The sedimentation of cloud ice is reduced which increases the cloud life time. One reason is that in boxes containing a large number concentration of ice crystals the terminal velocity is low. Hence ice crystals stay in the 20 layer. On the opposite a narrow distribution leads to less ice formation at the beginning and therefore a higher LWP but later on the freezing rate is enhanced.

In summary, a change in $\sigma_{\text {ICNC }}$ leads to small changes in cloud microphysical properties since IWP is low while a change in $\sigma_{\mathrm{CDNC}}$ affects the freezing and precipitation rate because autoconversion and freezing depends on the size of the cloud droplets. A change in the standard deviations of mass and number concentration at the same time compensates some changes in microphysical variables because e.g. an increase in LWP does not necessarily lead to an increase in precipitation when CDNC is enhanced as well.

\section{Sub-column algorithm in \\ ECHAM5-HAM}

S. Jess et al.

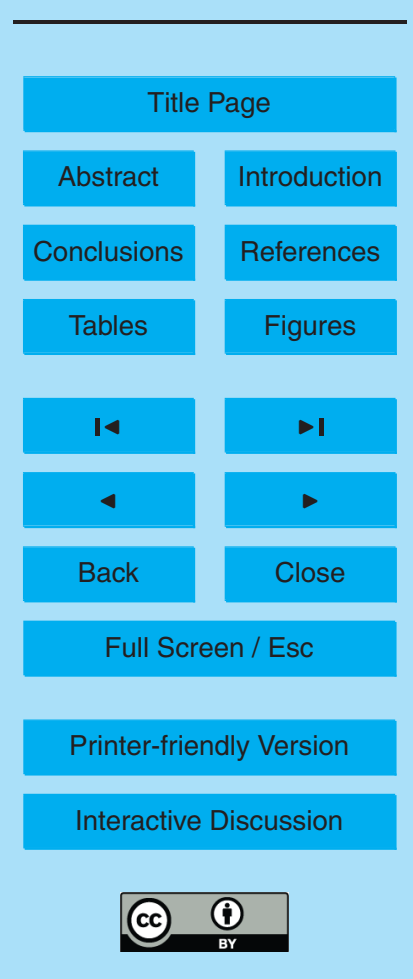




\subsection{Variation in vertical correlation}

In order to evaluate the choice of the vertical correlation, two different sensitivity simulations were performed where first no correlation between the cloud properties in different layers $(\mathrm{HETcor}=0)$ and second a perfect correlation $(\mathrm{HETcor}=1)$ is assumed. For the 5 perfect correlation the same mass and/or number concentration of water and ice is filled into the sub-box directly below if both layers are cloudy. The properties of the last cloudy sub-box of each level are chosen that the average values are conserved.

Figure 9 shows the changes in cloud properties for different assumptions of the vertical correlation for the EPIC campaign. It can be seen that changes occur but they are smaller than the differences between the simulations REF and HOM and the differences when changing the standard deviation.

Larger changes occur in case of the multi-layer mixed-phase cloud from the MPACE campaign (Fig. 10). While changes in LWP are rather small, a strong increase in precipitation is seen in the simulation without vertical correlation, which is caused by enhanced accretion on 6 October and first enhanced freezing and second stronger sedimentation of cloud ice through the cloud on 7 October. The reason for the large difference between the simulations is a low ice water mixing ratio in the upper cloudy levels. If the correlation between the levels is assumed to be high, then the same IWC is filled into the lower level and the majority of sub-boxes contain only small amounts of IWC while only few boxes have larger amounts of cloud ice where the ice crystals may sublimate below the cloud. The simulations HET and HETcor $=1$ are similar since there is a strong correlation between the vertical levels probably caused by low wind shear.

In summary, the vertical correlation seems to be less important for a water cloud only, because cloud droplets do not sediment in the ECHAM model due to low terminal velocities and a coarse vertical resolution while the vertical correlation inside a mixedphase cloud can strongly affect the microphysical processes (Fig. 10).

\section{Sub-column algorithm in \\ ECHAM5-HAM}

S. Jess et al.

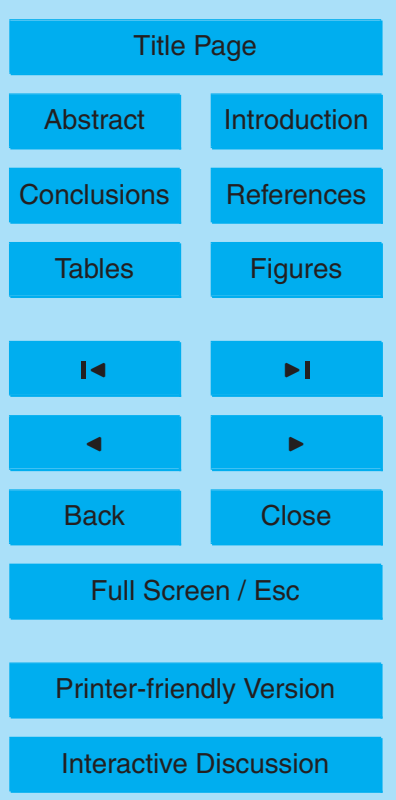




\section{Conclusions}

In this paper a statistical sub-column algorithm was included into the ECHAM5 SCM for a more physical treatment of subgrid variability in precipitation formation. Each column of the model is divided into 20 sub-columns, which are independent and contain 5 random microphysical values from log-normal distributions (simulation HET).

The precipitation formation and changes in microphysical variables were investigated for a liquid cloud in the tropics (EPIC campaign) and a multi-layer mixed-phase cloud over Alaska (MPACE campaign) to evaluate the algorithm.

The simulations show an increase in the precipitation efficiency due to the inhomo10 geneities at the beginning of the simulation. For the EPIC field campaign the new algorithm was able to produce a higher precipitation rate earlier and a reduced LWP in better agreement with the observations. In simulation HET for MPACE A the vertical extension of the cloud was reduced due to sedimentation of ice. In the first time steps precipitation falls as snow as observed during the campaign. The inhomogeneities led 15 to an enhanced precipitation rate over several time steps. In general, simulation HET shows no improvement as compared to the reference simulation for the MPACE case.

Sensitivity studies showed a small sensitivity to a change in the number of subcolumns for the homogeneous distribution for both campaigns. A change in the distribution width shows a large sensitivity. The narrow distribution is close to the simulation HOM following Jakob and Klein (1999). The vertical correlation between cloud layers is less important for the EPIC campaign, but the presence of ice crystals and enhanced accretion inside the mixed-phase cloud of the MPACE campaign yields a larger sensitivity to the vertical correlation but mainly in terms of the precipitation amount and IWP. Especially for the EPIC campaign, the inhomogeneities in simulation HET are necessary to form more precipitation.

In future, the new algorithm will be used to simulate the present and future climate in the global climate model ECHAM5 and to study the impacts of subgrid variability on the distribution and amount of precipitation. Initially in the GCM we will assume

\section{Sub-column algorithm in \\ ECHAM5-HAM}

S. Jess et al.

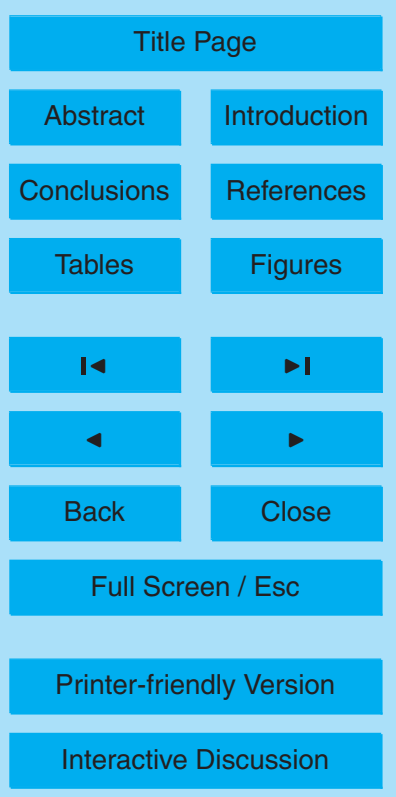

Interactive Discussion 
that the chosen standard deviations are valid for all clouds in the GCM. With the more physical treatment of precipitation in the sub-columns the washout of aerosols needs to be treated accordingly. This will have implications for the indirect aerosol effect. Improvements may account for a more consistent treatment of the statistical cloud 5 cover scheme and distribution of cloud properties. Further the algorithm could be coupled with the radiation parameterization for which the cloud fraction is an important parameter. Also subgrid variability strongly influences the optical thickness of a cloud (Carlin et al., 2002; Pincus et al., 2006). Our method coupled to the radiation routine as introduced by Räisänen et al. (2004) should save computing time as compared to the 10 use of a high-resolution model (Grabowski, 2001) because only the cloudy columns will be divided into sub-columns. Furthermore it might be possible to improve the precipitation formation and reduce errors in the radiation budget and distribution of precipitation.

Acknowledgements. We want to thank Martina Krämer from Forschungszentrum Jülich (Ger15 many), Hugh Morrison from National Center for Atmospheric Research, Boulder, Colorado (USA), Matthew D. Shupe from Cooperative Institute for Research in Environmental Sciences, University of Colorado/NOAA, Boulder, Colorado (USA), Zhien Wang from Department of Atmospheric Science, University of Wyoming (USA) and David D. Turner from Space Science and Engineering Center, University of Wisconsin (USA) for providing us data and also Sylvaine 20 Ferrachat for technical support.

\section{References}

Baker, M. B.: Cloud microphysics and climate, Science, 276(5315), 1072-1078, 1997. 9338

Barker, H. W., Pincus, R., and Morcrette, J. J.: The Monte Carlo independent column approximation: application within largescale models, paper presented at the GCSS-ARM Workshop on the Representation of cloud systems in large-scale models, global energy and water cycle exp. cloud syst. stud.atmos. radiat. meas. program, Kananaskis, Alberta, Canada, 20-24 May 2002. 9339

\section{Sub-column algorithm in ECHAM5-HAM}

S. Jess et al.

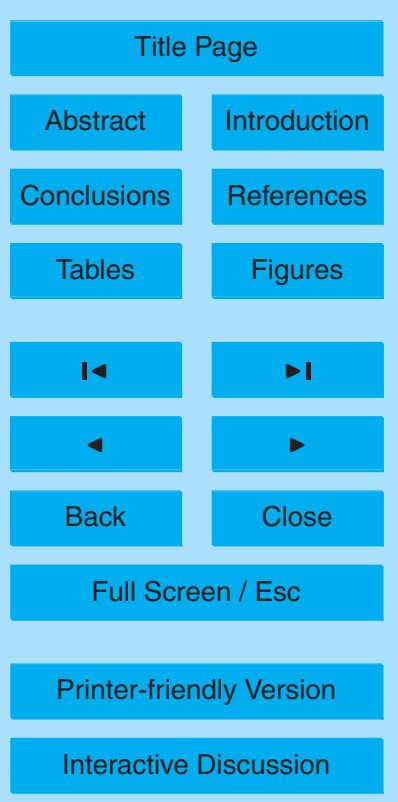

Interactive Discussion 
Bretherton, C., Uttal, T., Fairall, C., Yuter, S., Weller, R., Baumgardner, D., Comstock, K., Wood, R., and Raga, G.: The EPIC 2001 stratocumulus study, B. Am. Meteorol. Soc., 85, 967-977, 2004. 9340, 9345

Carlin, B., Fu, Q., Lohmann, U., Mace, G. G., Sassen, K., and Comstock, J. M.: High-cloud horizontal inhomogeneity and solar albedo bias, J. Climate, 15, 2321-2339, 2002. 9337, 9357

Chahine, M. T.: The hydrological cycle and its influence on climate, Nature, 359, 373-380, 1992. 9337

Comstock, J. M., Wood, R., Yuter, S. E., and Bretherton, C. S.: Reflectivity and rain rate in and below drizzling stratocumulus, Q. J. Roy. Meteor. Soc., 130, 2891-2919, 2004. 9345

Dong, X. and Mace, G. G.: Profiles of low-level stratus cloud microphysics deduced from ground-based measurements, J. Atmos. Ocean. Tech., 20, 42-53, 2003. 9345

Gayet, J.-F., Ovarlez, J., Shcherbakov, V., Ström, J., Schuhmann, U., Minikin, A., Auriol, F., Petzold, A., and Monier, M.: Cirrus cloud microphysical and optical properties at southern and northern midlatitudes during the INCA experiment, J. Geophys. Res., 109, D20206, doi:10.1029/2004JD004803, 2004. 9344

Grabowski, W. W.: Coupling cloud processes with the large-scale dynamics using the cloudresolving convection parameterization (CRCP), J. Atmos. Sci., 58, 978-997, 2001. 9339, 9340, 9357

20 Gultepe, I. and Isaac, G. A.: Liquid water content and temperature relationship from aircraft observations and its applicability to GCMs, J. Climate, 10, 446-452, 1996. 9344

Gultepe, I. and Isaac, G. A.: Aircraft observations of cloud droplet number concentration: implications for climate studies, Q. J. Roy. Meteor. Soc., 130, 2377-2390, 2004. 9344

Hogan, R. J. and Illingworth, A. J.: Parameterizing ice cloud inhomogeneity and the overlap of inhomogeneities using cloudradar data, J. Atmos. Sci., 60, 756-767, 2003. 9342

Hogg, D. C., Guiraud, F. O., Snider, J. B., Decker, M. T., and Westwater, E. R.: A steerable dual-channel microwave radiometer for the measurements of water vapor and liquid in the troposphere, J. Appl. Meteorol., 22, 789-806, 1983. 9345

Jakob, C. and Klein, S. A.: The role of vertically varying cloud fraction in the parameterization 30 of microphysical processes in the ECMWF model, Q. J. Roy. Meteor. Soc., 125, 941-965, 1999. 9339, 9340, 9341, 9342, 9343, 9344, 9348, 9351, 9356, 9362

Jakob, C. and Klein, S. A.: A parameterization of the cloud and precipitation overlap for use in general-circulation models, Q. J. Roy. Meteor. Soc., 126, 2525-2544, 2000. 9337

\section{Sub-column algorithm in ECHAM5-HAM}

S. Jess et al.

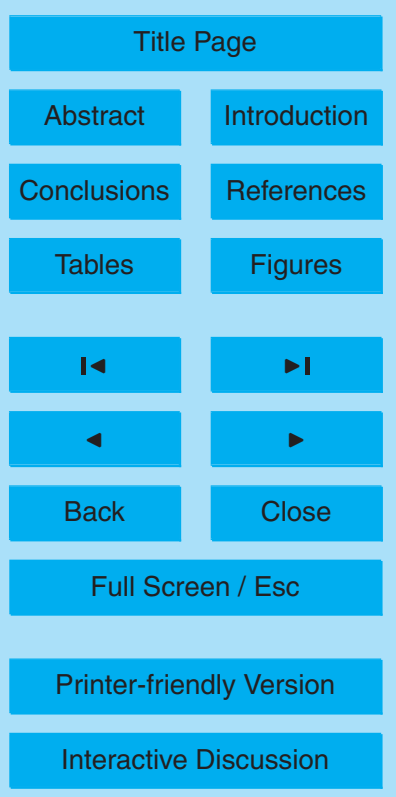


Khairoutdinov, M. and Kogan, Y.: A new cloud physics parameterization in a large-eddy simulation model of marine stratocumulus, Mon. Weather Rev., 128, 229-243, 2000. 9341

Kiehl, J. T. and Trenberth, K. E.: Earth's annual global mean energy budget, B. Am. Meteorol. Soc., 78, 197-208, 1997. 9337

5 Klein, S. A., McCoy, R. B., Morrison, H. , Ackerman, A. S., Avramov, A., de Boer, G., Chen, M., Cole, J. N. S., Del Genio, A. D., Falk, M., Foster, M. J., Fridlind, A., Golaz, J.-C., Hashino, T., Harrington, J. Y., Hoose, C., Khairoutdinov, M. F., Larson, V. E., Liu, X., Luo, Y., McFarquhar, G. M., Menon, S., Neggers, R. A. J., Park, S., Poellot, M. R., Schmidt, J. M., Sednev, I., Shipway, B. J., Shupe, M. D., Spangenberg, D. A., Sud, Y. C., Turner, D. D., Veron, D. E., 10 von Salzen, K., Walker, G. K., Wang, Z., Wolf, A. B., Xie, S., Xu, K.-M., Yang, F., and Zhang, G.: Intercomparison of model simulations of mixed-phase clouds observed during the ARM Mixed-phase Arctic Cloud Experiment, Part I: Single layer cloud, Q. J. Roy. Meteor. Soc., 135, 979-1002, 2009. 9346

Larson, V. E., Wood, R., Field, P. R., Golaz, J.-C., Haar, T. H. V., and Cotton, W. R.: Systematic 15 biases in the microphysics and thermodynamics of numerical models that ignore subgridscale variability, J. Atmos. Sci., 58, 1117-1128, 2001. 9337

Lohmann, U. and Roeckner, E.: Design and performance of a new cloud microphysics scheme developed for the ECHAM general circulation model, Clim. Dynam., 12, 557-572, 1996. 9341

20 Lohmann, U., Spichtinger, P., Jess, S., Peter, T., and Smit, H.: Cirrus clouds and ice supersaturated regions in a global climate model, Environ. Res. Lett., 3 (4), doi:10.1088/17489326/3/4/045022, 2008. 9341, 9344

Manton, M. J. and Cotton, W. R.: Formulation of approximate equations for modeling moist deep convection on the mesoscale, Atmos. Sci. Pap., 266, Dep. Atmos. Sci., Colo. State

25 Univ., Fort Collins, 1977. 9337

Morrison, $\mathrm{H}$. and Gettelman, A.: A new two-moment bulk stratiform cloud microphysics scheme in the community atmosphere model, Version 3 (CAM3), Part I: Description and numerical tests, J. Climate, 21, 3642-3659, 2008. 9337

Morrison, H., McCoy, R. B., Klein, S. A., Xie, S., Luo, Y., Avramov, A., Chen, M., Cole, J. N. S., Falk, M., Foster, M. J., Del Genio, A. D., Harrington, J. Y., Hoose, C., Khairoutdinov, M. F., Larson, V. E., Liu, X., McFarquhar, G. M., Poellot, M. R., von Salzen, K., Shipway, B. J., Shupe, M. D., Sud, Y. C., Turner, D. D., Veron, D. E., Walker, G. K., Wang, Z., Wolf, A. B., Xu, K.-M., Yang, F., and Zhang, G. : Intercomparison of model simulations of mixed-phase

\section{Sub-column algorithm in ECHAM5-HAM}

S. Jess et al.

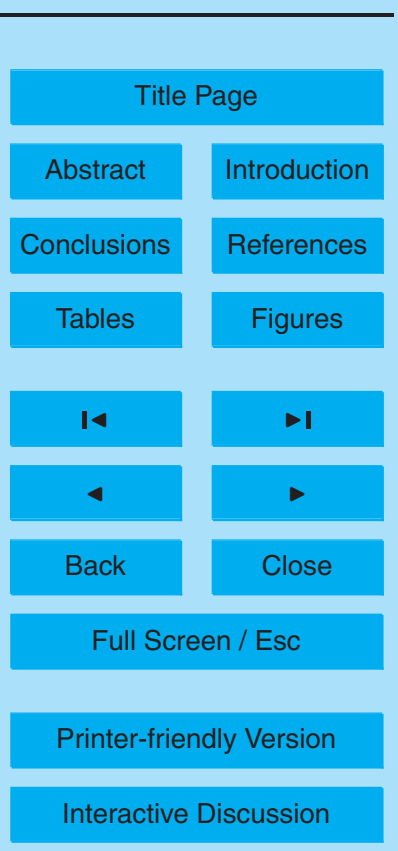


clouds observed during the ARM Mixed-Phase Arctic Cloud Experiment, Part II: Multilayer cloud, Q. J. Roy. Meteor. Soc., 135, 1003-1019, 2009. 9346, 9349, 9350

Pincus, R., McFarlane, S. A., and Klein, S. A.: Albedo bias and the horizontal variability of clouds in subtropical marine boundary layers: observations from ships and satellites, J. Geophys. Res., 104(D6), 6183-6191, 1999. 9337

Pincus, R., Barker, H. W., and Morcrette, J. J.: A fast, flexible, approximate technique for computing radiative transfer in inhomogeneous cloud fields, J. Geophys. Res., 108, 4376, doi:10.1029/2002JD003322, 2003. 9339

Pincus, R., Hemler, R., and Klein, S. A.: Using stochastically generated subcolumns to represent cloud structure in a large-scale model, Mon. Weather Rev., 134, 3644-3656, 2006. 9357

Posselt, R. and Lohmann, U.: Introduction of prognostic rain in ECHAM5: design and single column model simulations, Atmos. Chem. Phys., 8, 2949-2963, doi:10.5194/acp-8-29492008, 2008. 9347, 9348

15 Räisänen, P., Barker, H. W., Khairoutdinov, M. F., Li, J., and Randall, D. A.: Stochastic generation of subgrid-scale cloudy columns for large-scale models, Q. J. Roy. Meteor. Soc., 130, 2047-2068, 2004. 9339, 9340, 9343, 9357

Raschke, E., Ohmura, A., Rossow, W. B., Carlson, B. E., Zhang, Y.-C., Stubenrauch, C., Kottek, M., and Wild, M.: Cloud effects on the radiation budget based on ISCCP data (1991 to 1995), Int. J. Climatol., 25, 1103-1125, 2005. 9337

Roeckner, E., Bäuml, G., Bonaventura, L., Brokopf, R., Esch, M., Giorgetta, M., Hagemann, S., Kirchner, I., Kornblueh, L., Manzini, E., Rhodin, A., Schlese, U., Schulzweida, U., and Tompkins A. : The atmospheric general circulation model ECHAM5, Part I: Model description, Report 349, Max Planck Institute for Meteorology, Hamburg, Germany, 2003. 9341

Rotstayn, L. D.: On the "tuning" of autoconversion parameterizations in climate models, J. Geophys. Res., 105, doi:10.1029/2000JD900129, 15495-15507, 2000. 9337

Schiller, C., Krämer, M., Afchine, A., Spelten, N., and Sitnikov, N.: The ice water content of Arctic, mid latitude and tropical cirrus, J. Geophys. Res., 113(D24208), 12 pp., doi:10.1029/2008JD010342, 2008. 9344

30 Shupe, M. D., Matrosov, S. Y., and Uttal, T.: Arctic mixed-phase cloud properties derived from surface-based sensors at SHEBA, J. Atmos. Sci., 63, 697-711, 2006. 9350

Stier, P., Feichter, J., Kinne, S., Kloster, S., Vignati, E., Wilson, J., Ganzeveld, L., Tegen, I., Werner, M., Balkanski, Y., Schulz, M., Boucher, O., Minikin, A., and Petzold, A.: The aerosol-

\section{ACPD}

$11,9335-9374,2011$

\section{Sub-column algorithm in \\ ECHAM5-HAM}

S. Jess et al.

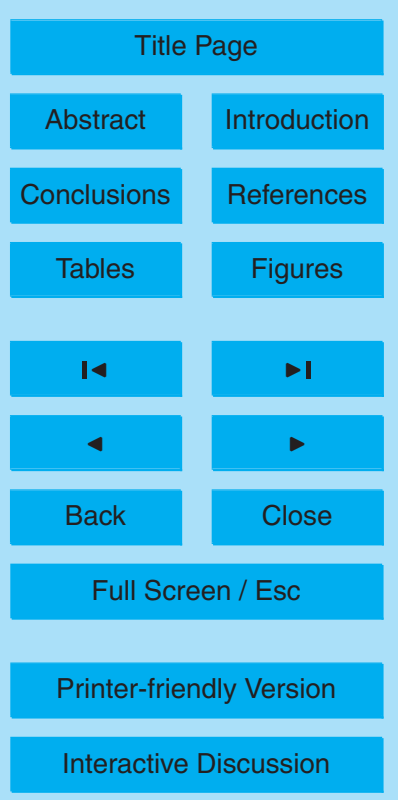


climate model ECHAM5-HAM, Atmos. Chem. Phys., 5, 1125-1156, doi:10.5194/acp-5-11252005, 2005. 9341

Tompkins, A.: A prognostic parameterization for the subgrid-scale variability of water vapor and clouds in large scale models and its use to diagnose cloud cover, J. Atmos. Sci., 59(12), 1917-1942, 2002. 9339, 9341

Tsushima, Y., Emori, S., Ogura, T., Kimoto, M., Webb, M. J., Williams, K. D., Ringer, M. A., Soden, B. J., Li, B. und Andronova, N.: Importance of the mixed-phase cloud distribution in the control climate for assessing the response of clouds to carbon dioxide increase: a multimodel study, Clim. Dynam., 27, 113-126, 2006. 9338

10 Turner, D., Clough, S., Liljegren, J., Clothiaux, E., Cady-Pereira, K., and Gaustad, K.: Retrieving liquid water path and precipitable water vapor from the atmospheric radiation measurement (ARM) microwave radiometers, IEEE T. Geosci. Remote, 45, 3680-3690, 2007. 9349

Verlinde, J., Harrington, J. Y., McFarquhar, G. M., Yannuzzi, V. T., Avramov, A., Greenberg, S., Johnson, N., Zhang, G., Poellot, M. R., Mather, J. H., Turner, D. D., Eloranta, E. W., Zak, B. D., Prenni, A. J., Daniel, J. S., Kok, G. L., Tobin, D. C., Holz, R., Sassen, K., Spangenberg, D., Minnis, P., Tooman, T. P., Ivey, M. D., Richardson, S. J., Bahrmann, C. P., Shupe, M.,DeMott, P. J., Heymsfield, A. J. and Schofield, R. : The mixed-phase arctic cloud experiment, B. Am. Meteorol. Soc., 88, 205-221, 2007. 9340, 9346

Weinman, J. A. and Swarztauber, P. N.: Albedo of a stratified medium of isotropically scattering particles, J. Atmos. Sci., 25, 497-501, 1968. 9338

Zuidema, P., Westwater, E. R., Fairall, C., and Hazen, D.: Ship-based liquid water path estimates in marine stratocumulus, J. Geophys. Res., 110(D20206), doi:10.1029/2005JD005833, 2005. 9345

\section{ACPD}

11, 9335-9374, 2011

\section{Sub-column algorithm in \\ ECHAM5-HAM}

S. Jess et al.

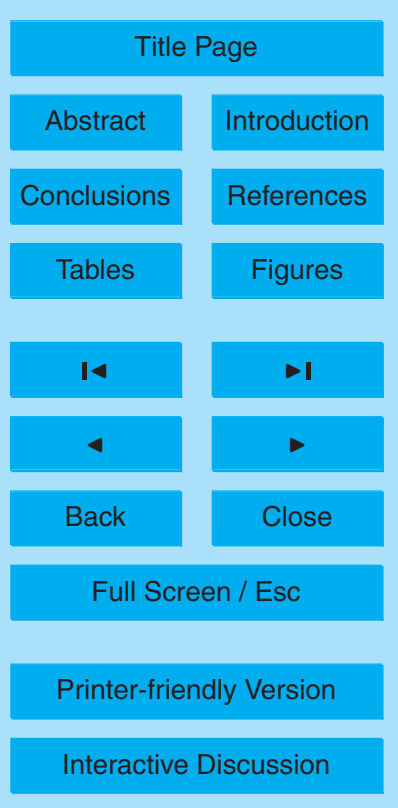




\section{ACPD}

11, 9335-9374, 2011

Table 1. Set-up for the three different single column model simulations.

\begin{tabular}{ll}
\hline Simulation & Description \\
\hline REF & $\begin{array}{l}\text { Reference simulation with the original } \\
\text { model ECHAM5.5 with a changed order } \\
\text { of the cloud microphysical processes } \\
\text { (see Sect. 2) }\end{array}$ \\
HOM & $\begin{array}{l}\text { As simulation REF but } 20 \text { sub-columns } \\
\text { with a homogeneous distribution following } \\
\text { Jakob and Klein (1999) (the mean } \\
\text { cloud condensate is used for each } \\
\text { cloudy sub-box of each layer) }\end{array}$ \\
& $\begin{array}{l}\text { As simulation HOM but using log-normal } \\
\text { distributions of LWC and CDNC (for } \\
\text { the EPIC and the MPACE case study) } \\
\text { as well as IWC and ICNC (for the } \\
\text { MPACE case study) }\end{array}$ \\
\hline
\end{tabular}

\section{Sub-column algorithm in \\ ECHAM5-HAM}

S. Jess et al.

Title Page

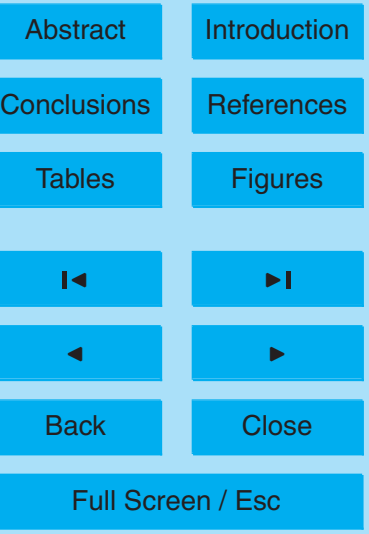

Printer-friendly Version

Interactive Discussion 


\section{ACPD}

$11,9335-9374,2011$

Table 2. Sensitivity studies for the EPIC campaign with the single column model for different number of sub-columns: for HET20 the following standard deviations are used: $\sigma_{\mathrm{LWC}}=1.5$, $\sigma_{\mathrm{CDNC}}=1.6$. The values are given as cloud cover (\%), liquid water path (LWP) $\left(\mathrm{g} \mathrm{m}^{-2}\right)$, cloud droplet number concentration (CDNC) $\left(\mathrm{cm}^{-3}\right)$ and precipitation $\left(\mathrm{mm} \mathrm{day}^{-1}\right)$.

\begin{tabular}{lccccc}
\hline Simulation & Sub-columns & Cloud cover & LWP & CDNC & Precipitation \\
\hline HOM20 & 20 & 73 & 148.76 & 88 & 0.278 \\
HOM21 & 21 & 77 & 139.96 & 93 & 0.276 \\
HOM37 & 37 & 74 & 145.01 & 85 & 0.291 \\
HOM42 & 42 & 72 & 145.40 & 84 & 0.265 \\
HOM50 & 50 & 75 & 146.54 & 86 & 0.272 \\
HOM100 & 100 & 73 & 146.60 & 85 & 0.263 \\
HOM500 & 500 & 73 & 145.28 & 85 & 0.263 \\
HET20 & 20 & 69 & 104.36 & 84 & 0.322 \\
HET40 & 40 & 75 & 117.00 & 90 & 0.408 \\
HET60 & 60 & 70 & 105.91 & 83 & 0.333 \\
\hline
\end{tabular}

\section{Sub-column algorithm in \\ ECHAM5-HAM}

S. Jess et al.

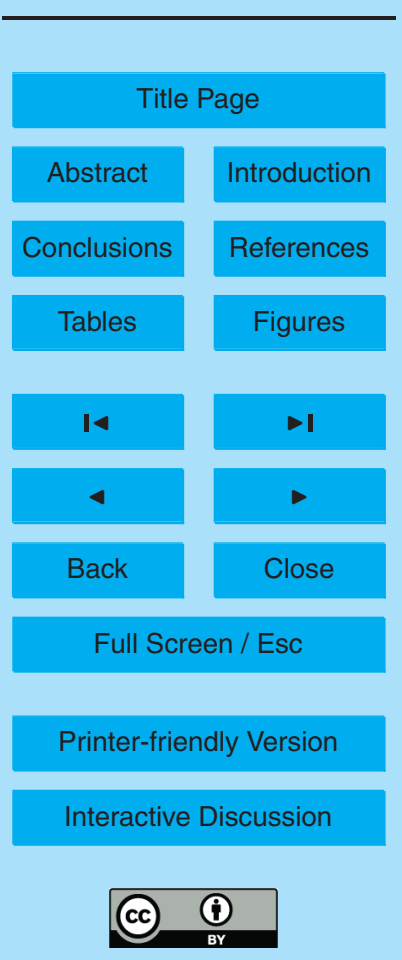




\section{ACPD}

$11,9335-9374,2011$

Table 3. Sensitivity studies for the EPIC campaign with the single column model with 20 subcolumns for different values of the standard deviation for cloud cover, CDNC, LWP and IWP are liquid water path and ice water path. All values are averaged over the simulation period.

\begin{tabular}{lcccccc}
\hline Simulation & $\sigma_{\mathrm{CDNC}}$ & $\sigma_{\mathrm{LWC}}$ & Cloud cover & LWP & CDNC & Precipitation \\
\hline OBS & & & 94 & 102.08 & 107 & 0.188 \\
REF & & & 73 & 144.52 & 90 & 0.260 \\
HOM & 1.6 & 1.5 & 69 & 104.36 & 78 & 0.278 \\
HET & 1.5 & 1.3 & 76 & 130.54 & 90 & 0.405 \\
HET $\sigma_{\text {CDNC }}=1.3$ & & 74 & 118.30 & 81 & 0.348 \\
HET $\sigma_{\text {CDNC }}=1.4$ & 1.5 & 1.4 & 68 & 99.65 & 78 & 0.312 \\
HET $\sigma_{\text {CDNC }}=1.5$ & 1.5 & 1.5 & 69 & 104.36 & 78 & 0.332 \\
HET $\sigma_{\text {CDNC }}=1.6$ & 1.5 & 1.6 & 68 & 119.55 & 76 & 0.309 \\
HET $\sigma_{\text {CDNC }}=1.7$ & 1.5 & 1.7 & 68 & 101.01 & 76 & 0.333 \\
HET $\sigma_{\text {CDNC }}=1.8$ & 1.5 & 1.8 & 74 & 105.35 & 84 & 0.366 \\
HET $\sigma_{\text {CDNC }}=1.9$ & 1.5 & 1.9 & 73 & 141.69 & 90 & 0.263 \\
HET $\sigma_{1.01}$ & 1.01 & 1.01 & 73 & 69.17 & 83 & 0.436 \\
HET $\sigma_{\text {DOUBLE }}$ & 3.0 & 3.2 & 74 & & & \\
\hline
\end{tabular}

\section{Sub-column algorithm in \\ ECHAM5-HAM}

S. Jess et al.

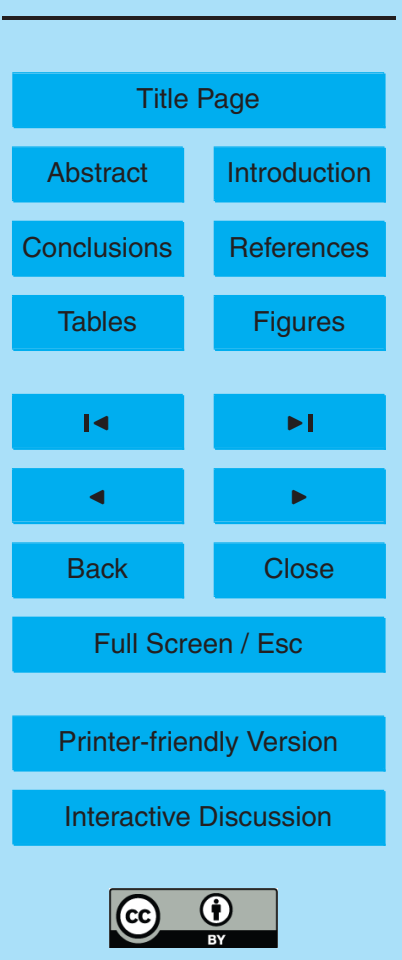




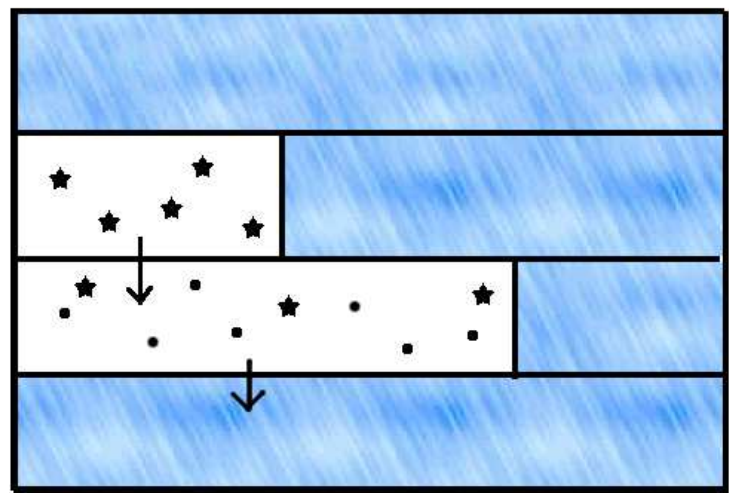

\section{ACPD}

11, 9335-9374, 2011

\section{Sub-column algorithm in \\ ECHAM5-HAM}

S. Jess et al.

(a) Precipitation fluxes in a single column of ECHAM5.

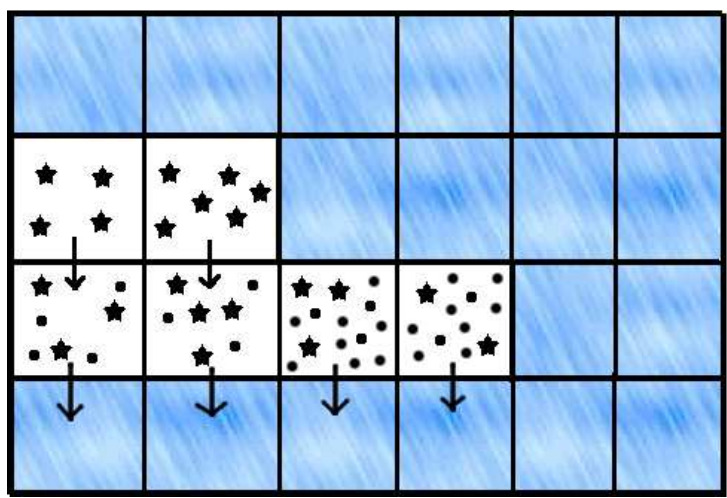

Title Page

Abstract

Introduction

Conclusions

References

Tables

Figures

14

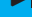

4

\section{Back}

Close

\section{Full Screen / Esc}

Printer-friendly Version

Fig. 1. Schematic of the vertical transport of precipitation. In the original version (a) the fluxes from above (stars describe snow flakes and circles rain drops) are allowed to interact with the whole cloud in the level below before the weighting is calculated while for the sub-column algorithm (b) only the sub-boxes below the upper layer can interact with the precipitation from above (arrows show transport).

Interactive Discussion 


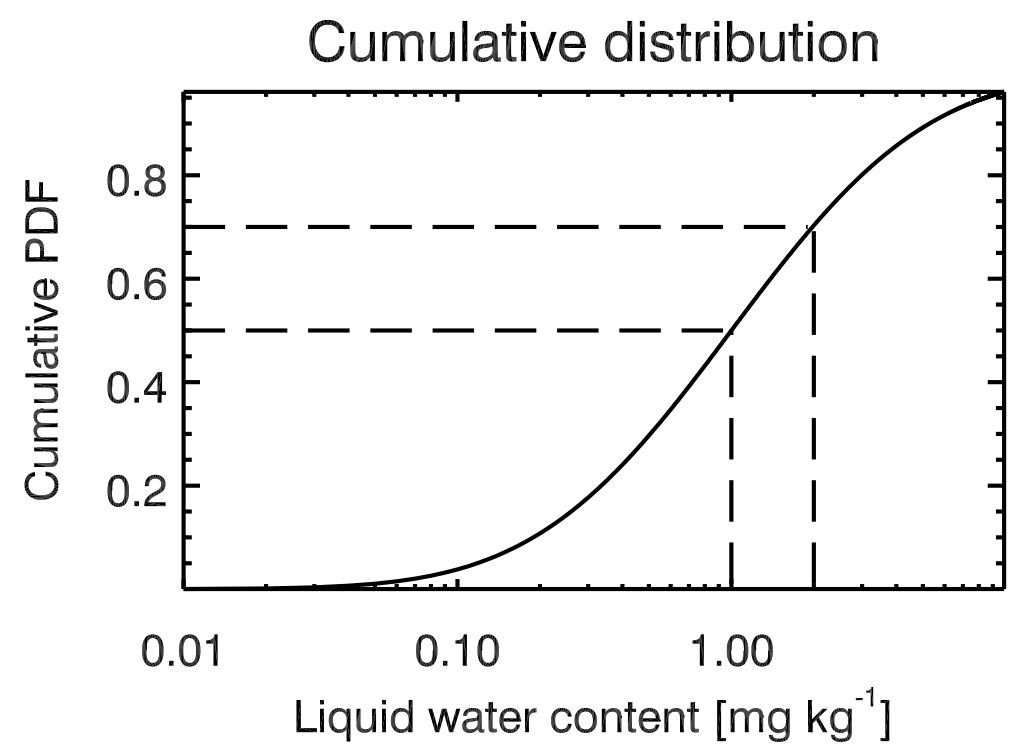

Fig. 2. Cumulative distribution of a probability frequency distribution (PDF). For every y-value there is a corresponding $x$-value (liquid water content in $\mathrm{mg} \mathrm{kg}^{-1}$ ) which could be chosen randomly to fill into a cloudy sub-box.

\section{ACPD}

11, 9335-9374, 2011

\section{Sub-column algorithm in \\ ECHAM5-HAM}

S. Jess et al.

Title Page

Abstract

Introduction

Conclusions

References

Tables

Figures

14

4

Back

Close

\section{Full Screen / Esc}

Printer-friendly Version

Interactive Discussion 


\section{ACPD}

11, 9335-9374, 2011
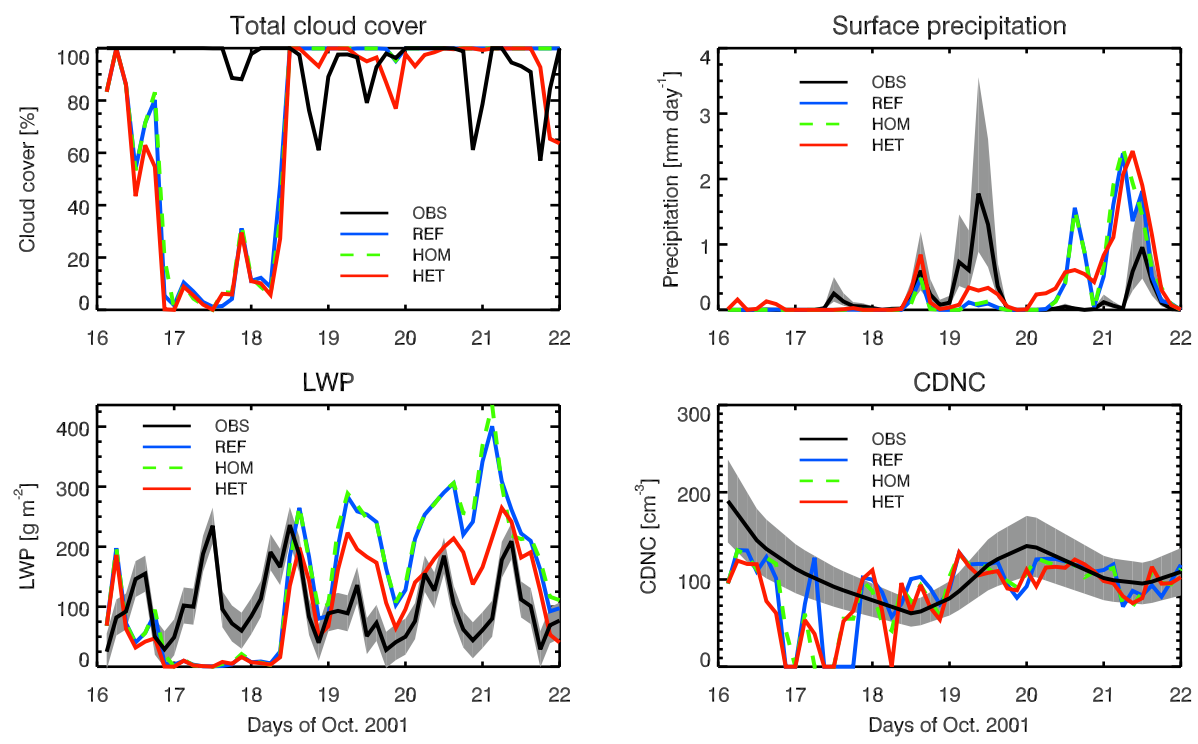

Fig. 3. Time-series of observed and simulated cloud cover (\%), observed precipitation with an uncertainty of a factor of two (grey shaded area) and modeled precipitation ( $\mathrm{mm} \mathrm{day}^{-1}$ ), retrieved liquid water path (LWP) $\left(\mathrm{g} \mathrm{m}^{-2}\right)$ with an uncertainty of $30 \mathrm{~g} \mathrm{~m}^{-2}$ (grey shaded area) and simulated LWP and retrieved cloud droplet number concentration (CDNC) $\left(\mathrm{cm}^{-3}\right)$ with an uncertainty of $25 \%$ (grey shaded area) and modeled CDNC for the EPIC campaign. All quantities have been averaged over $3 \mathrm{~h}$.

\section{Sub-column algorithm in \\ ECHAM5-HAM}

S. Jess et al.

Title Page

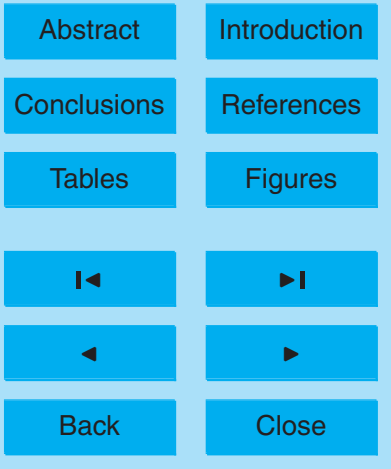

Full Screen / Esc

Printer-friendly Version

Interactive Discussion 


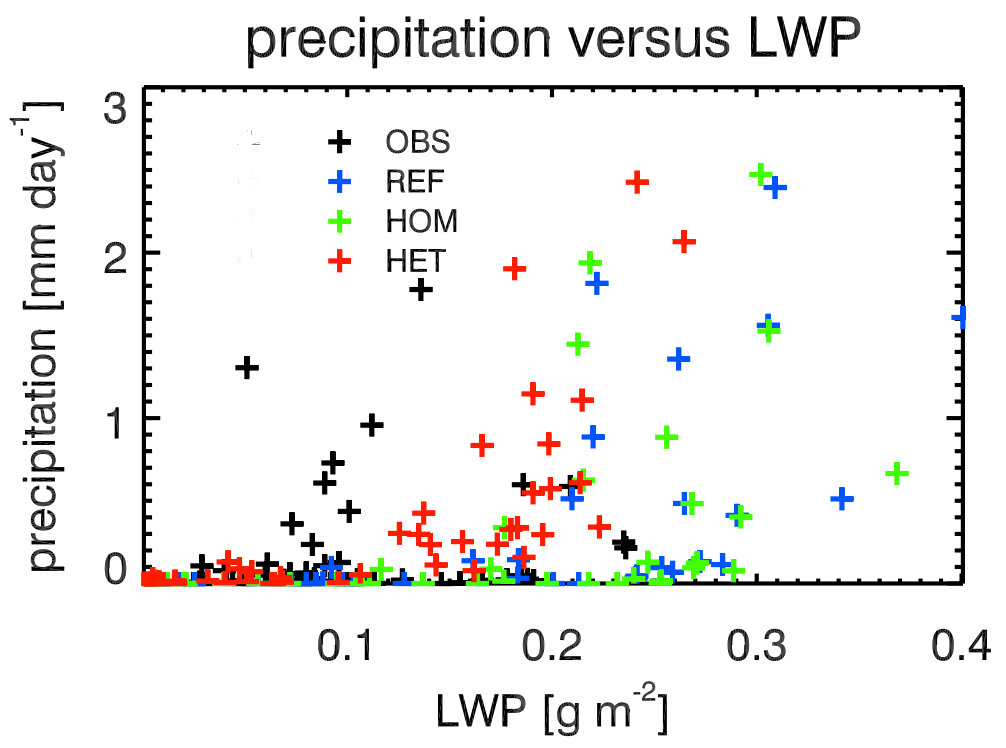

Fig. 4. Relationship between precipitation and LWP for all time steps of the EPIC campaign.
11, 9335-9374, 2011

Sub-column algorithm in ECHAM5-HAM

S. Jess et al.

Title Page

Abstract

Introduction

Conclusions

References

Tables

Figures

14

4

Back

Close

Full Screen / Esc

Printer-friendly Version

Interactive Discussion 


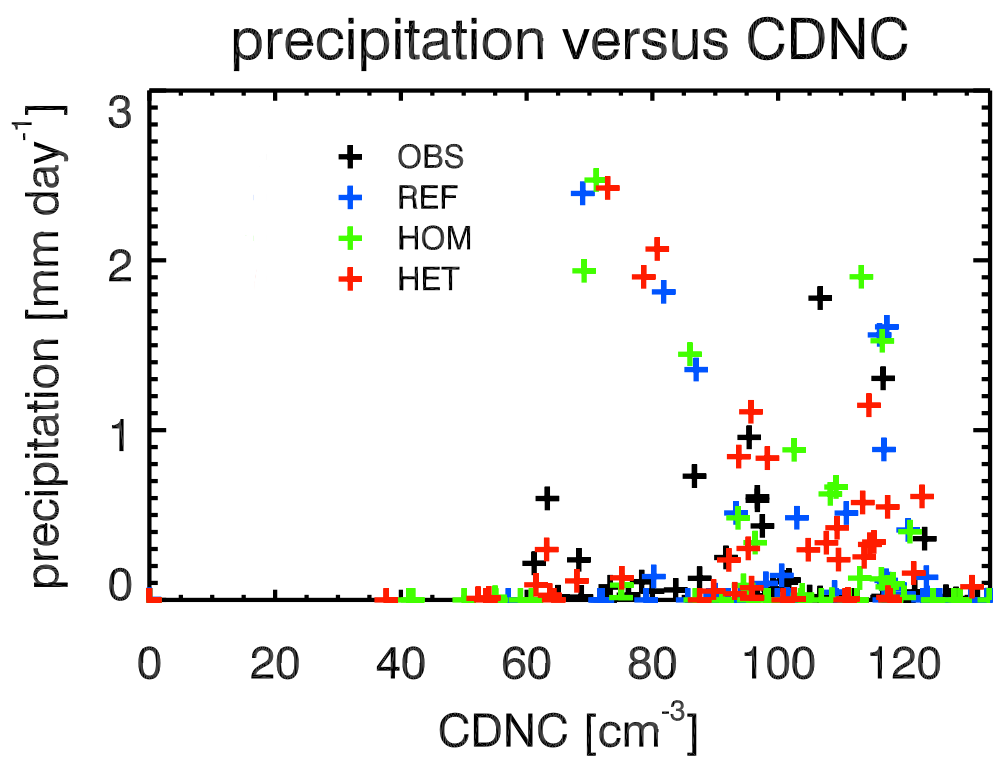

Fig. 5. Relationship between precipitation and CDNC for all time steps of the EPIC campaign.
11, 9335-9374, 2011

Sub-column algorithm in ECHAM5-HAM

S. Jess et al.

Title Page

Abstract

Introduction

Conclusions

References

Tables

Figures

14

4

Back

Close

Full Screen / Esc

Printer-friendly Version

Interactive Discussion 

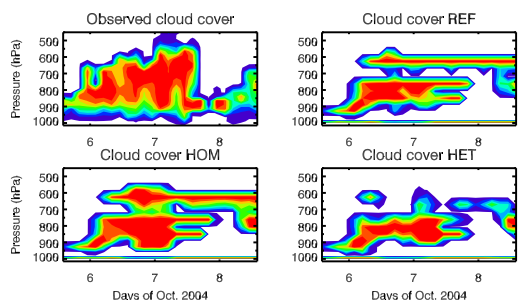

${ }^{6}$ Cloud cover HET $^{8}$

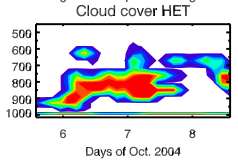

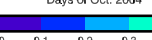

$\stackrel{7}{{ }^{7}}$ Days of Oct. 2004

LWP

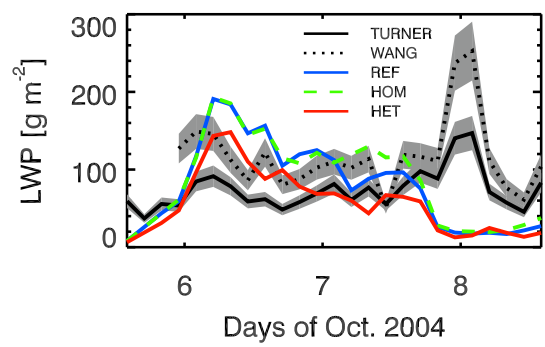

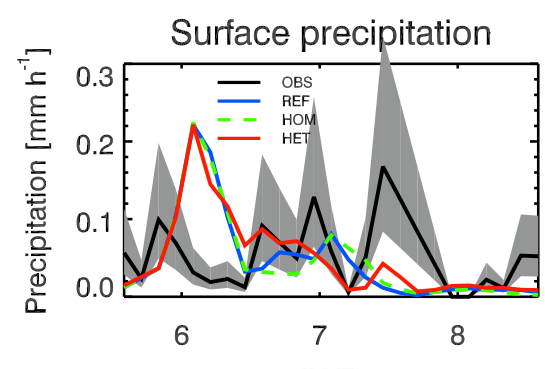

IWP

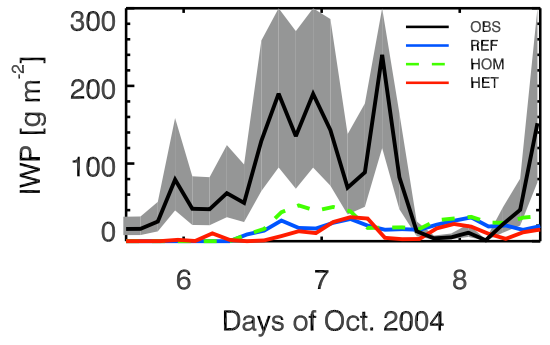

Fig. 6. Time-height plots of ARSCL (active remote sensing of cloud layer)-derived cloud fraction and simulated cloud fraction as well as time-series of observed precipitation (black) with an uncertainty of a factor of two (grey shaded area) and modeled precipitation $\left(\mathrm{mm} \mathrm{h}^{-1}\right)$, liquid water path (LWP) $\left(\mathrm{g} \mathrm{m}^{-2}\right)$ retrieved from measurements by TURNER (black solid line) and WANG (black dotted line) with an uncertainty of $\pm 15 \%$ (grey shaded area) and simulations and ice water path (IWP) $\left(\mathrm{g} \mathrm{m}^{-2}\right)$ retrieved from measurements (black) with an uncertainty of a factor of two (grey shaded area) and simulations for MPACE period A. All quantities have been averaged over $3 \mathrm{~h}$.

\section{ACPD}

11, 9335-9374, 2011

\section{Sub-column algorithm in \\ ECHAM5-HAM}

S. Jess et al.

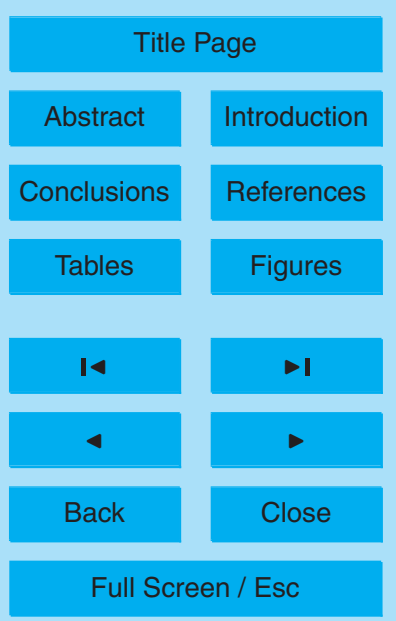

Printer-friendly Version

Interactive Discussion 


\section{ACPD}

11, 9335-9374, 2011
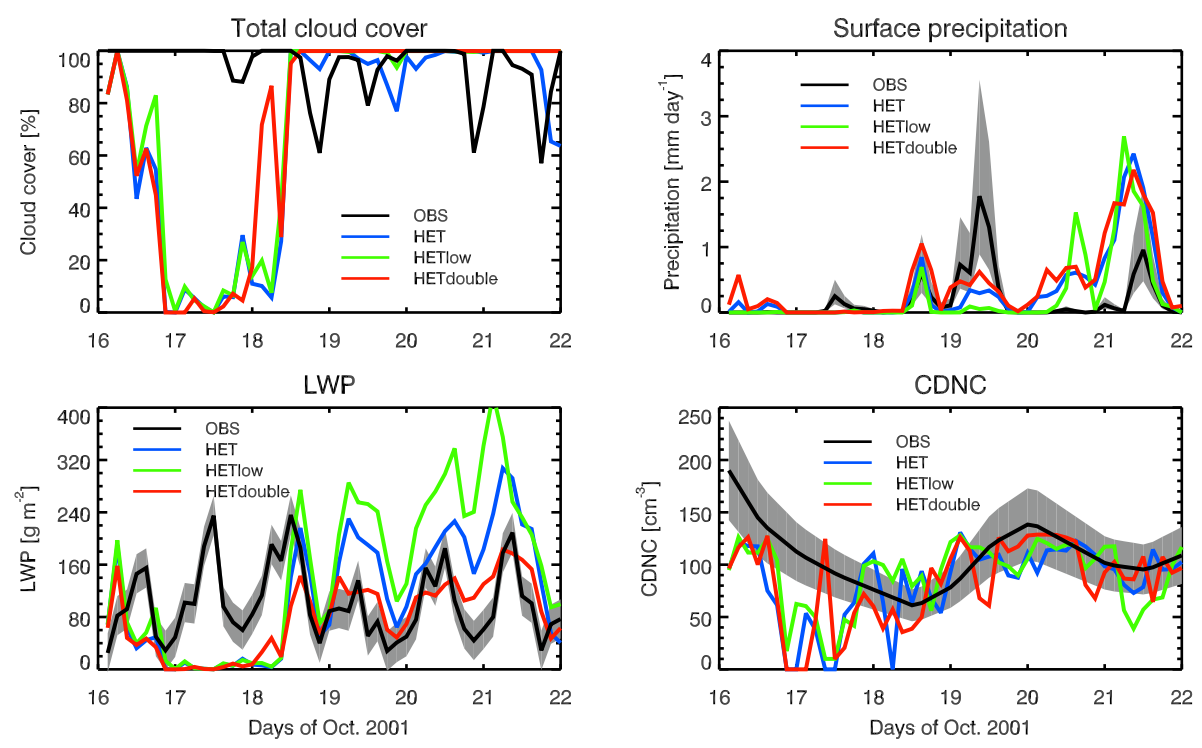

Fig. 7. As Fig. 3 for the EPIC campaign but for simulations with a changed standard deviation with $\sigma_{\mathrm{LWC}}=1.01$ and $\sigma_{\mathrm{CDNC}}=1.01$ (HETlow) and $\sigma_{\mathrm{LWC}}=3.0$ and $\sigma_{\mathrm{CDNC}}=3.2$ (HETdouble).

\section{Sub-column algorithm in ECHAM5-HAM}

S. Jess et al.

Title Page

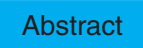

Introduction

Conclusions

References

Tables

Figures
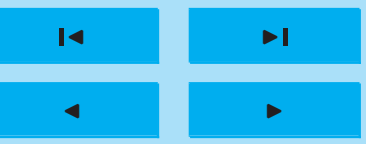

Back

Close

Full Screen / Esc

Printer-friendly Version

Interactive Discussion

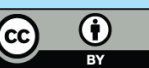




\section{ACPD}

11, 9335-9374, 2011
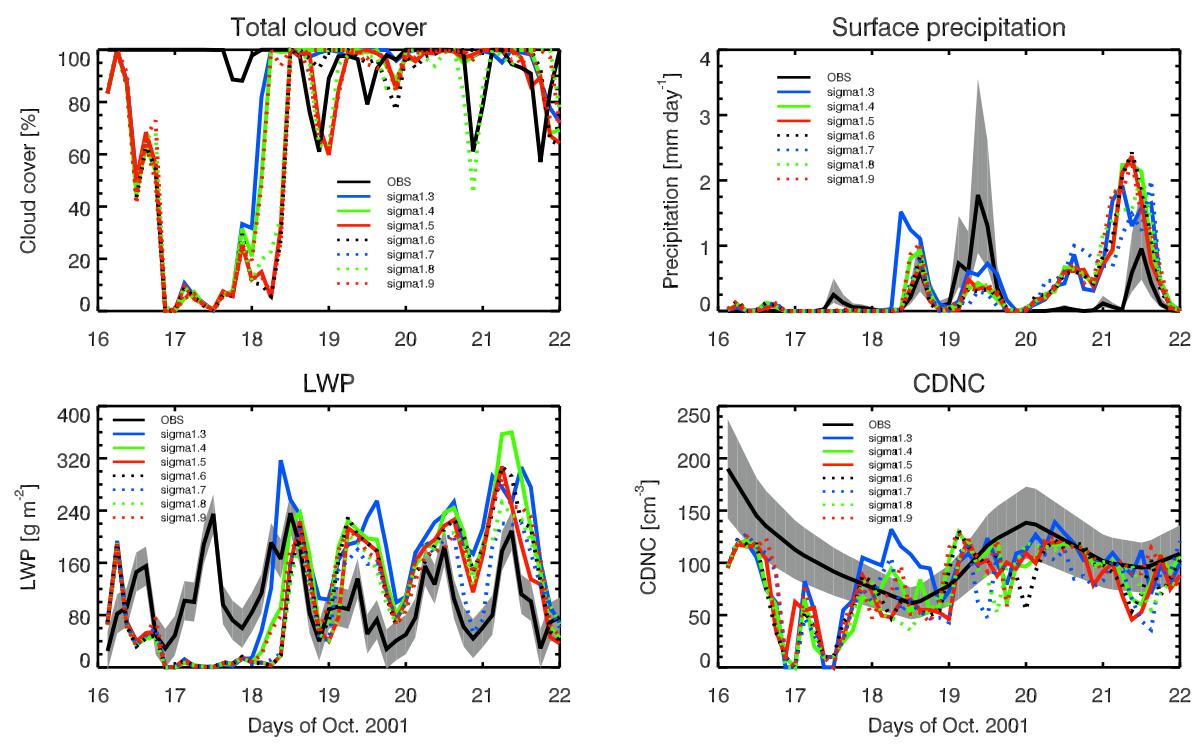

Fig. 8. As Fig. 3 for the EPIC campaign but for simulations with a changed standard deviation for $\sigma_{\mathrm{CDNC}}$.

\section{Sub-column algorithm in ECHAM5-HAM}

S. Jess et al.

Title Page

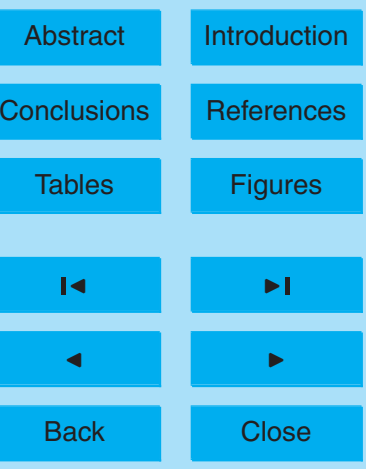

Full Screen / Esc

Printer-friendly Version

Interactive Discussion 


\section{ACPD}

$11,9335-9374,2011$
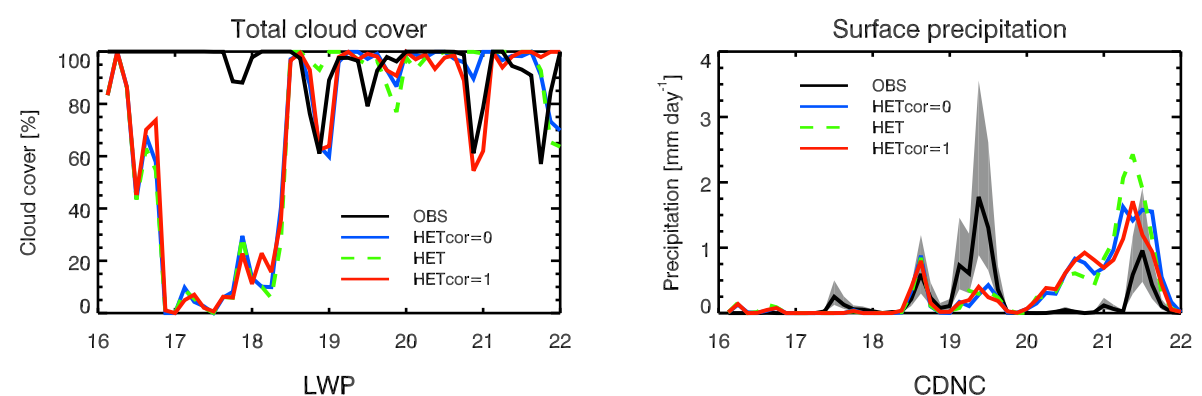

\section{Sub-column algorithm in ECHAM5-HAM}

S. Jess et al.
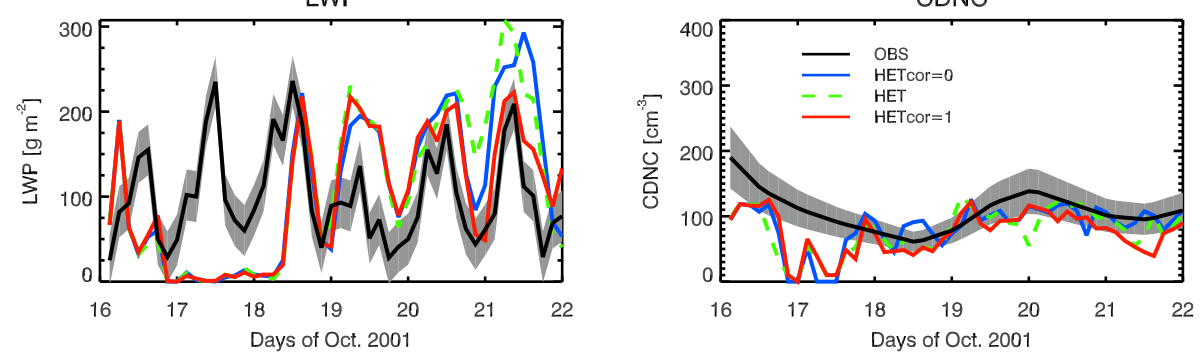

Fig. 9. As Fig. 3 for the EPIC campaign but with a change in the vertical correlation of cloud properties: HETcor $=0$ describes no vertical correlation and HETcor $=1$ displays perfect vertical correlation.

\section{Full Screen / Esc}

Printer-friendly Version 


\section{ACPD}

11, 9335-9374, 2011

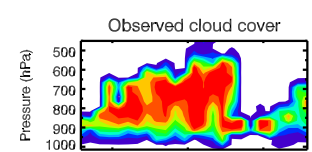

${ }^{6}$ Cloud cover HET $^{8}$
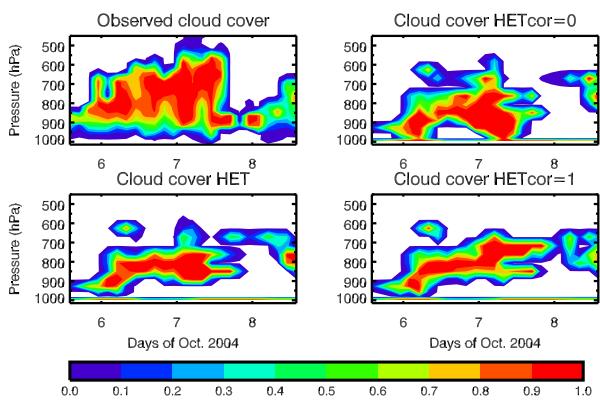

\section{LWP}

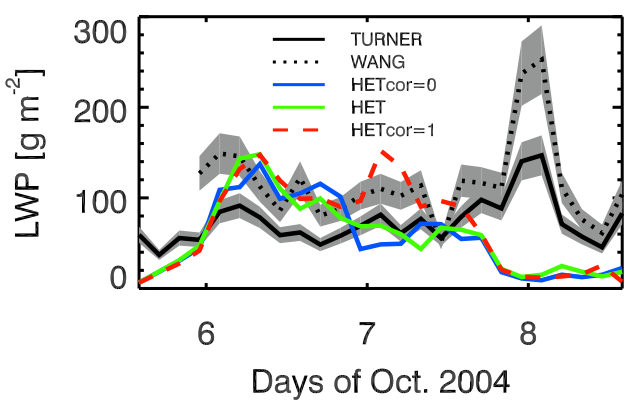

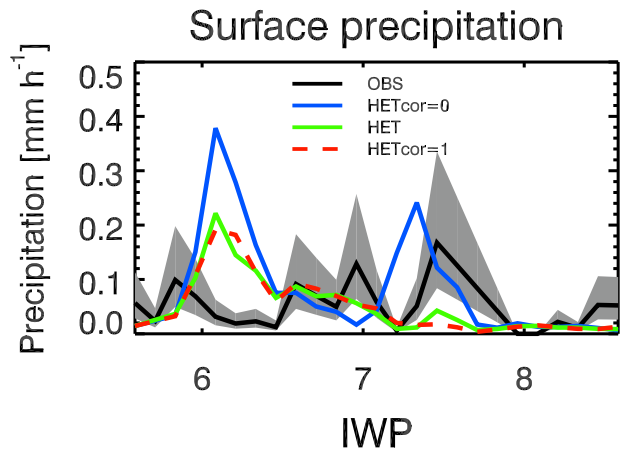

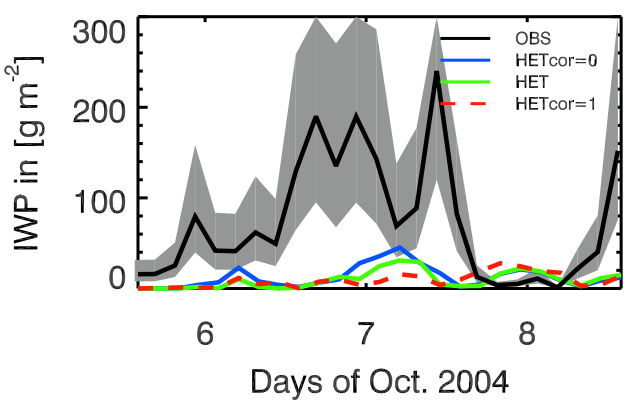

Fig. 10. As Fig. 6 for the MPACE campaign but with a change in the vertical correlation of cloud properties: HETcor $=0$ describes no vertical correlation and HETcor $=1$ displays perfect vertical correlation.

\section{Sub-column algorithm in \\ ECHAM5-HAM}

S. Jess et al.

Title Page

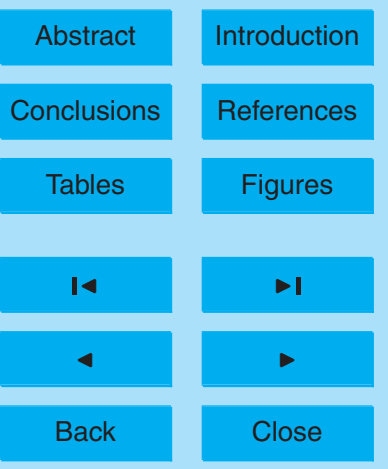

Full Screen / Esc

Printer-friendly Version

Interactive Discussion 